University of Texas at El Paso

\title{
DigitalCommons@UTEP
}

Open Access Theses \& Dissertations

2015-01-01

\section{The Effects of Task Demands and Word Frequency on Language Source Encoding}

Elva Natalia Strobach Oronoz

University of Texas at El Paso, enstrobach@utep.edu

Follow this and additional works at: https://digitalcommons.utep.edu/open_etd

Part of the Other Languages, Societies, and Cultures Commons, and the Psychology Commons

\section{Recommended Citation}

Strobach Oronoz, Elva Natalia, "The Effects of Task Demands and Word Frequency on Language Source Encoding" (2015). Open Access Theses \& Dissertations. 1164.

https://digitalcommons.utep.edu/open_etd/1164

This is brought to you for free and open access by DigitalCommons@UTEP. It has been accepted for inclusion in Open Access Theses \& Dissertations by an authorized administrator of DigitalCommons@UTEP. For more information, please contact lweber@utep.edu. 


\title{
THE EFFECTS OF TASK DEMANDS AND WORD FREQUENCY ON LANGUAGE SOURCE ENCODING
}

\author{
ELVA-NATALIA STROBACH ORONOZ \\ Department of Psychology
}

\section{APPROVED:}

Wendy S. Francis, Ph.D., Chair

Jon Amastae, Ph.D.

Ashley Bangert, Ph.D.

Stephen Crites, Ph.D.

Ana I. Schwartz, Ph.D.

Charles Ambler, Ph.D.

Dean of the Graduate School 


\section{Copyright (C)}

by

Elva-Natalia Strobach Oronoz

2015 


\section{Dedication}

To my beautiful sons Lucca and Diego, in the short time that I've known you, you've taught me more than I could learn in a lifetime. Being your mother has been the most profound experience of my life. To my dearest husband, Beto, I could not have done this without you. You've kept life together as I chased this crazy dream of mine, I will forever be thankful. You complete me in more ways than one, I love you. Mom, I did it! You get to call me doctor now. I could not have completed this dissertation without the help of my amazing research assistants, Maria Ranson, Ana Villela, and Ricardo Paez. Maria, you were with me since the initial stages, helping me come up with sentences, watching me program, and running most of the people in these studies. I am forever grateful. Finally, to my advisor, Wendy, thank you for always being there for me, for teaching me, for your patience, and for your never-ending kindness. 


\title{
THE EFFECTS OF TASK DEMANDS AND WORD FREQUENCY ON LANGUAGE SOURCE ENCODING
}

\author{
by \\ ELVA-NATALIA STROBACH ORONOZ, M.A. \\ DISSERTATION \\ Presented to the Faculty of the Graduate School of \\ The University of Texas at El Paso \\ in Partial Fulfillment \\ of the Requirements \\ for the Degree of
}

DOCTOR OF PHILOSPHY

Department of Psychology

THE UNIVERSITY OF TEXAS AT EL PASO

December 2015 


\begin{abstract}
Source memory effects have been relatively unexplored in bilingual memory. Bilinguals have to perform certain source encoding operations to successfully determine the appropriate language from context. These operations have not been examined from a long-term memory perspective, and are not incorporated into models of source monitoring. Further, language source information is not incorporated into the major models of bilingual language processing. Five experiments examined bilinguals' language source monitoring for low- and high-frequency words in English and Spanish. Each experiment placed different processing demands on participants. In Experiment 1, participants studied a mixed-language word list, then were subsequently tested for language source discrimination using pictures. In Experiment 2, participants read English and Spanish sentences at study and were tested on language source using pictures. Experiment 3 had participants name pictures in English or Spanish at study, and language source discrimination was tested using pictures at test. In Experiment 4 participant heard words in English and Spanish and had to discriminate language source information using pictures. Finally, in Experiment 5, participants translated words at study and language source discrimination was tested using pictures. Across all five experiments we observed a lowfrequency word advantage in language source discrimination. Similarly, a production advantage arose such that the language source of words that were produced was more accurately discriminated than for words that were comprehended. The results from these five experiments suggest that language should be incorporated into the major model of source memory as a salient source retrieval cue. Further, the results add evidence to a growing body of literature examining bilingual processing from a long-term memory perspective and inform the current models of bilingual processing.
\end{abstract}




\section{Table of Contents}

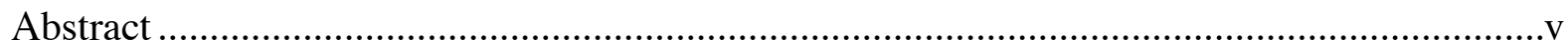

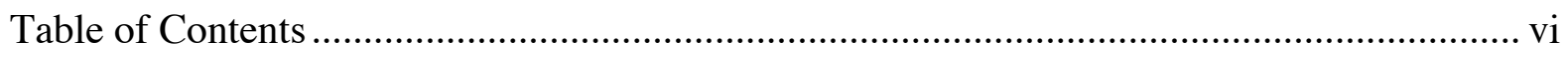

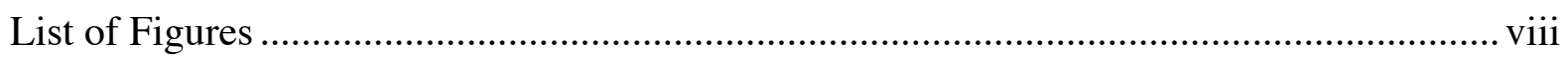

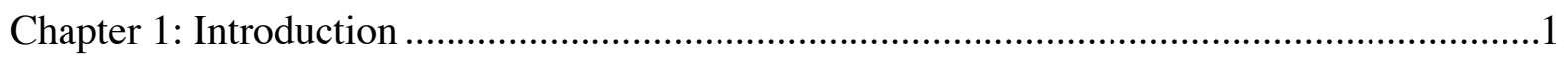

1.1 Source Memory and the Source-Monitoring Framework ......................................

1.2 Recognition for Source, Language Source, and Bilingual Word

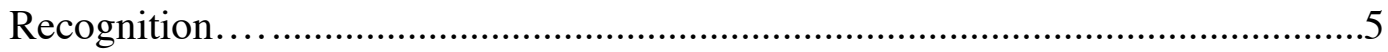

1.3 Bilingual Processing Models .................................................................

1.4 Bilingual Evidence of Non-Selectivity in Lexical Decision and

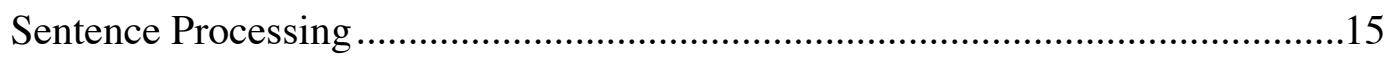

1.5 Bilingual Production Performance ....................................................................18

1.6 Bilingual Auditory Speech Perception.............................................................27

1.7 Phonotactic and Syntactic Constraints on Language Access and

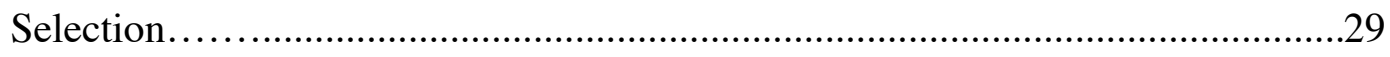

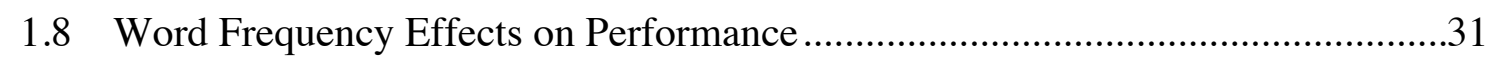

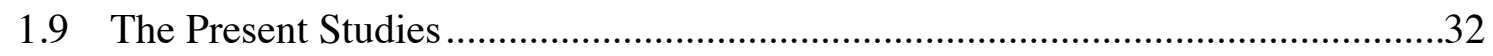

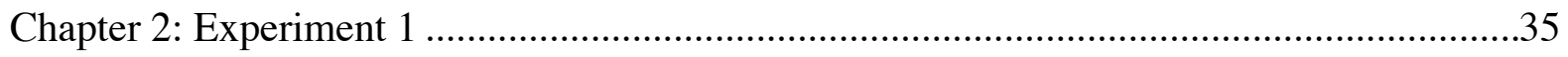

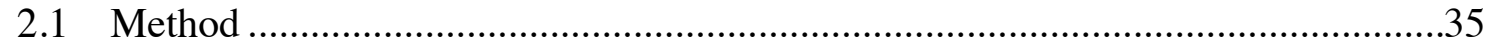

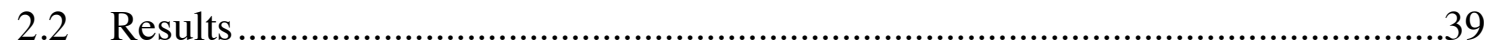

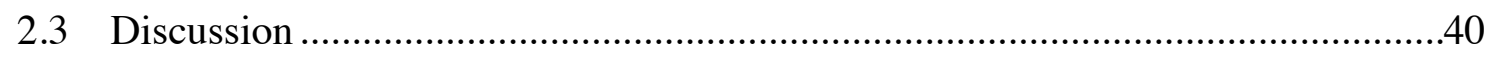

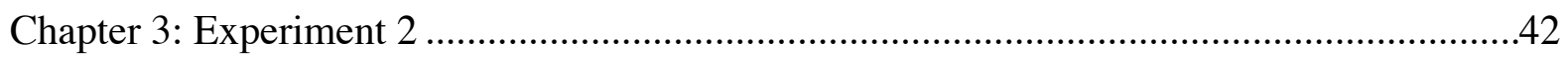

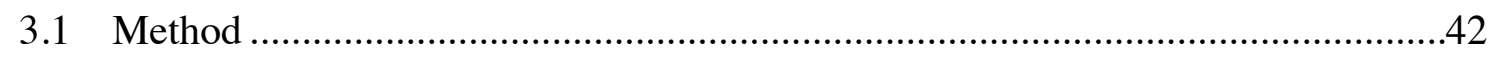

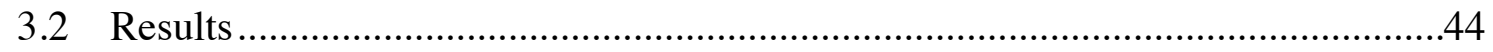

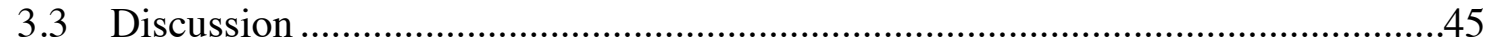

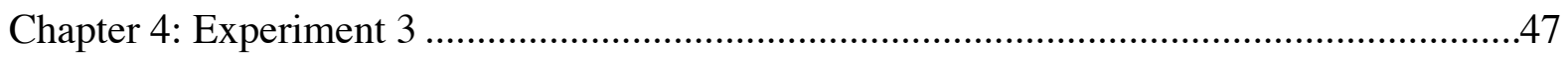

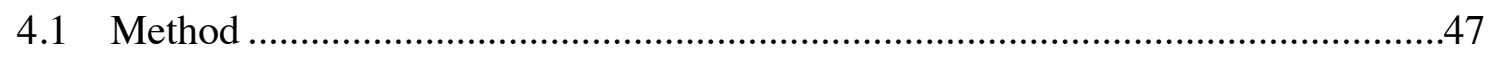

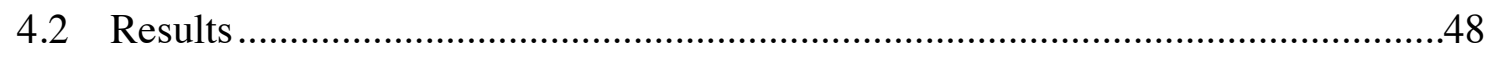

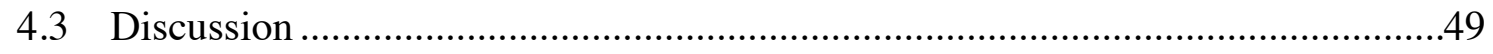




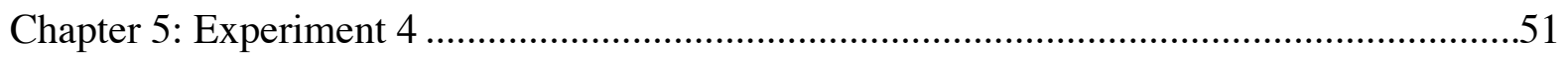

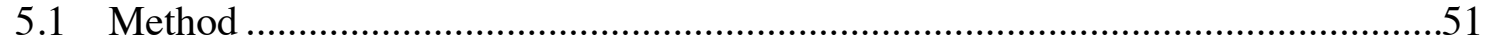

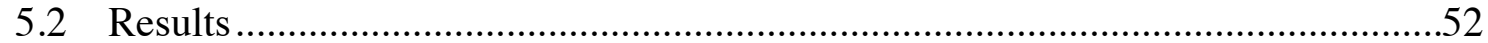

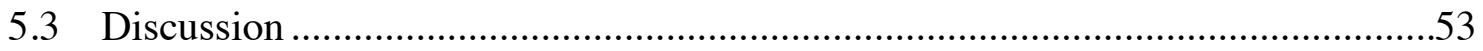

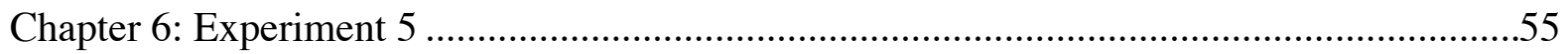

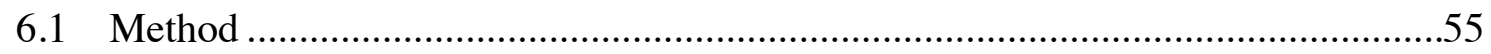

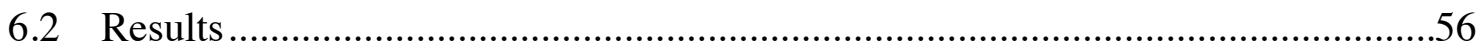

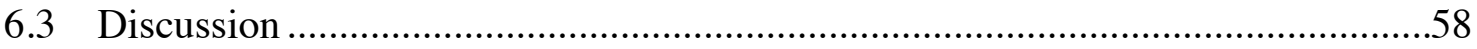

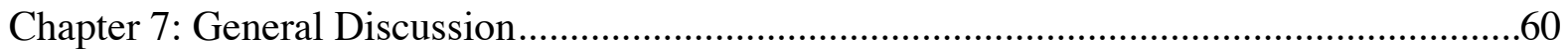

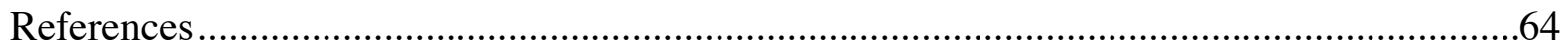

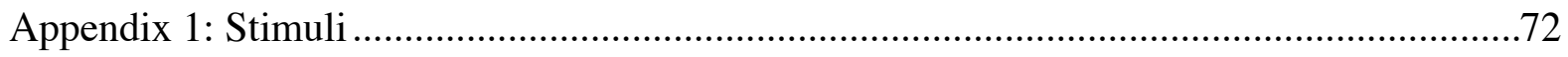

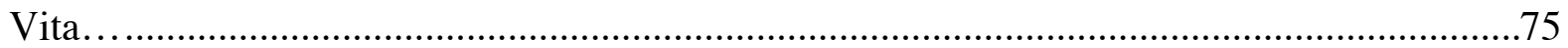




\section{List of Figures}

Figure 3.1: Discrimination Scores for Low- and High-Frequency Words Presented in Isolation or

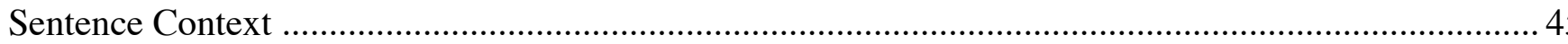

Figure 5.1: Discrimination Scores for Low- and High-Frequency Words as a Function of Perceptual and Conceptual Task Demands

Figure 6.1: Discrimination Scores for Low- and High-Frequency Words as a Function of Comprehension and Production. 


\section{Chapter 1: Introduction}

The question of whether language plays an important role in long-term memory has been asked and addressed in multiple ways over the last few decades. Indeed, one of the first reviews of language representation in long term memory argued decisively that language played as big a role in encoding as other perceptual and conceptual features (McCormack, 1976). However, the question of how language source information is encoded into long-term memory is relatively unexplored. At issue is how a bilingual stores language source information, episodically. That is, when processing auditory, visual, or articulatory information, at what point in processing does the bilingual encode for whether the information is in language A or language $\mathrm{B}$, and how does that information become available for episodic retrieval? Bilinguals are highly skilled at determining the appropriate language from context. When a bilingual hears, sees, or seeks to produce a word, rarely does the non-target language create interference in the form of errors, despite both languages being active at the same time and recruiting the same brain structures during processing (van Heuven, Schriefers, Dijkstra, \& Hagoort, 2008). Research has not yet established whether language source information is an important processing component in bilingual cognition. This dissertation investigates how language source information is represented in long-term memory.

Currently, the main model of source memory is underspecified with respect to how language source information is represented and subsequently retrieved from long-term memory. Similarly, models of bilingual language processing are underspecified with respect to the extent that language source information influences long term retention. The current study seeks to bridge the knowledge gaps between these two literatures to gain a broader understanding of how language influences long-term retrieval; and how the effects of language information interact with word frequency, as well as task demands placed on participants.

The main account of source retrieval, the source-monitoring framework, (Johnson 1988; Johnson, Hashtroudi, \& Lindsay, 1993) is underspecified with regard to the effects of language 
membership information on long-term source retrieval, the framework also lacks specificity with regard to the effects of different contextual cues on source retrieval. The three major models of bilingual language processing discuss issues relating to the language tag, language nodes, and representation for language source information (the terms are used interchangeably). The bilingual model of lexical access (BIMOLA; Grosjean, 1988) predicts a strong influence of language membership on auditory word recognition without relying on overt language cues or representations. The inhibitory control model (IC; Green, 1998) makes specific predictions regarding where language source information is stored within the bilingual lexicon, and how that information comes online depending on the nature of the task that the bilingual is performing. The model proposed by Costa and colleagues (Costa \& Caramazza, 1999; Costa, Miozzo, Caramazza, 1999) assumes that word processing occurs language selectively and that word representation is shared across languages only at the semantic level. Although the models account for much of the existing literature on auditory word perception, and spoken word production respectively; not much is known in terms of the memory representation for linguistic events that occur in a bilingual's two languages. Currently, models of bilingual processing are underspecified in terms of how language source information is encoded in long-term memory, and how it is subsequently retrieved. In addition to language source information, access to lexical and conceptual information is mediated by a variety of factors including word characteristics. One of the most significant factors that impact word recognition and lexical access is word frequency (e.g., Diana \& Reder, 2006; Duyck, Vanderelst, Desmet, \& Harsuiker, 2008). Wordfrequency is a factor that likely plays a role in language source encoding. The following sections detail the current state of knowledge relating to source memory, the three models of bilingual language processing addressed earlier, as well as significant findings relating to bilingual processing of language source information. 


\subsection{Source Memory and the Source-Monitoring Framework}

Source memory broadly refers to the ability to remember contextual details about memories (Johnson et al., 1993; Parker, 1995). This particular type of memory is independent from other types of memory, notably recognition memory. Amnesic patients who range in severity of cognitive deficit show impaired item source retrieval (source amnesia) despite good performance in recall and recognition tasks. The same is true of patients who perform badly in these tasks, suggesting that source memory for items is independent from recall and recognition memory (Shimamura \& Squire, 1987). Source memory follows an inverse U-shaped curve of development. Children are particularly bad at remembering source information; it is not until about age 6 that performance on source decisions is above chance (Ruffman, Rustin, Garnham, \& Parkin, 2001), and source retrieval also declines with age (Balota et al., 1999). Neurological activation of brain regions during source retrieval is predominantly localized in the frontal lobes, and is thought to rely heavily on executive control (Johnson et al., 1993; Parkin \& Leng, 1993; Wheeler, Stuss, \& Tulving, 1997).

The leading model used to account for source retrieval is the source-monitoring framework. The source-monitoring framework specified the existence of internal and external source memories. Internal source memories come from internal events (e.g., imagining we fed the dog). External memories come from externally derived experiences or actions (e.g., actually feeding the dog). Further, the framework specifies an internal/external monitoring system that is in charge of telling apart whether the source memories are real or imagined (e.g., internal or external; Johnson et al., 1993). Source discrimination is made on a variety of memory cues including perceptual and contextual information, semantic detail, affect, and the degree and type of cognitive operations used to encode the memory (Johnson et al., 1993). The framework has been extensively criticized (see Reyna \& Lloyd, 1997) for lacking specificity and for being so broad in its application that it is unfalsifiable. Indeed, Lindsay and Johnson (2000), concede that the framework lacks specificity as to how the cues interact to give rise to established source memory effects in the literature. 
One type of retrieval cue discussed in the source-monitoring framework is the cognitive operations used to form a memory. That is, the cognitive demands placed when a memory is encoded become part of the source for that particular memory. Experimentally, participants are better able to discriminate source if the memories differ in the cognitive operations used at study. For instance participants remembering between read or heard words. Suggesting that an association is made between cognitive operations used to encode a memory and subsequent source retrieval (Lindsay \& Johnson, 1991). Along the same lines, generating the information to be remembered leads to more accurate source retrieval than simply reading it (Nieznański, 2012), and this effect is particularly robust for items that are more difficult to generate. Perceptual cues are also proposed to play a role in source retrieval, and modality changes at encoding have no effect on source retrieval. Specifically, participants are as accurate at determining the perceptual details of a memory irrespective of whether it the information is read or presented aurally (Marsh, Cook, \& Hicks, 2006). Contextual cues, however, play a crucial role in source retrieval; the more unique the context in which a memory is experienced, the more likely that the source information is to be retrieved. This effect has been observed experimentally. Specifically, the sources of low frequency words and words with low context availability are more accurately discriminated than the sources of high-context and highfrequency words (Marsh et al., 2006). Accurate source memory retrieval seems to stem from the operations occurring at encoding more so than those taking place at retrieval. Evidence for this conclusion comes from research with children and older adults, who perform rather poorly on source memory tasks. When children as young as 3 (Crawley, Newcombre \& Bingman, 2010; Giles, Gopnik, \& Heyman, 2002), and older adults (Glisky, Rubin, \& Davidson, 2001) are explicitly told to monitor for source information they perform significantly better than when they are not vigilant to these types of information at encoding.

The findings in the source memory literature have strong implications for how we understand language source encoding and retrieval. First, we can directly test whether language plays a significant role as a source for memories by manipulating the cognitive operations used 
to encode linguistic information. Second, along with language manipulations, we can control for word characteristics, like frequency, to test how these in turn affect source retrieval. These manipulations should lead to patterns of results that can shed light on some of the specific questions that arise from the source-monitoring framework. Using bilingual materials allows us to uniquely test these effects while bridging the gap between the source memory and bilingual language processing literatures. The following sections will detail the central tenets of the three main models of bilingual processing and how they relate to language source retrieval.

\subsection{Recognition for Source, Language Source, and Bilingual Word Recognition}

Source memory involves a memory representation for an event in a particular context. For example, recalling a piece of information as well as recalling who provided the information. In essence, creating a source-dependent memory involves a binding operation (Chua, Chen, \& Park, 2006, p. 306), where the information bound includes a particular memory target and its relevant source. Source memory is different from item recognition memory in that item recognition involves a familiarity judgment and source memory involves a more detailed episodic trace of the item and the context in which it was encountered (Tosun, Vaid, \& Geraci, 2013); indeed, source and item recognition involve different neural substrates (Slotnick, Moo, Segal, \& Hart, 2003). Investigating source memory is particularly useful for investigating whether language source information is encoded into long-term memory. First, one can investigate how accurate bilinguals are in determining in which of their two languages a word was presented. Further, investigating source memory from a bilingual perspective also allows us to determine the processes involved in recognizing language source information.

In bilinguals, one can examine source memory by comparing whether individual language markings affect cross-language processing. Turkish and Korean are languages that mark for evidentiality (e.g., there is a distinct realization for conveying information you witnessed and second-hand information; Papafragou, Li, Choi, \& Han, 2007; Tosun, Vaid, \& Geraci, 2013). In general, evidentiality markings are acquired relatively late during language 
acquisition and are not thought to have direct conceptual mappings, instead evidentiality markings appear to be lexicalized (Papafragou et al., 2007). Turkish-English bilinguals perform differentially when recalling source information, recall that Turkish marks for evidentiality and English does not. Specifically, late acquirers of English seem to disregard second-hand source information, a pattern found in Turkish (their L1). Early acquirers of English however, show no difference in source recall for first and second-hand sources (Tosun, Vaid, \& Geraci, 2013). The findings illustrate a spill-over effect of the rules that govern encoding for source in Turkish into English processing, at least for late L2 learners. That is, linguistic markers that exist in only one language affect memory in both languages, this effect attenuates as linguistic experience increases in the $\mathrm{L} 2$.

The topic of language source information has been relatively unexplored. Few studies have examined bilingual performance on the recognition of language source or language of input. Early recall study findings showed that performance on mixed language lists was poorer than performance on pure language lists (Liepmann \& Saegert, 1974). A re-analysis of older recall studies in which participants are presented with mixed language item lists shows clustering of items by language upon recall, suggesting that items are reorganized in long-term memory and this reorganization is language dependent (Francis, 1999). Further, recognition studies where participants are presented with items in both their languages reveal that memory for language source is quite accurate (Kintsch, 1970; Saegert, Hamayan, \& Ahmar, 1975). Trilinguals who study words in two of their languages and are asked to recognize the original language of presentation in a third (neutral) language are very accurate in recognizing the language source of the words when the words were presented in isolation, but not as part of a larger sentence (Seagert, Hamayan, \& Ahmar, 1975). Nonetheless, bilinguals can accurately recall the language of input of sentences that were presented auditorially (Rose, Rose, King, \& Perez, 1975), but the degree of language source recognition is constrained by the type of stimulus list sentences are presented in, with recognition being more accurate for pure than mixed sentence lists (O'Neill \& 
Dion, 1983). The results of word recognition and recall suggest that bilinguals are quite skilled at recognizing whether an item was presented in a particular language.

One of the topics that remains unexplored by the recognition and recall experiments is the extent to which episodic retrieval is constrained by language source information. Recognition studies usually show participants a word in one of their languages and participants decide if the word is in the same or different language from original presentation. Alternatively, participants are presented with a third neutral language and they decide whether the word was presented in language A or language B. To date, there have been no studies that investigate language source from a conceptual standpoint. Indeed, studies that utilize cognates (recall that these items overlap, at least partially, in orthographic form) show that recognition for language is barely above chance (Cristoffanini, Kirsner, \& Milech, 1986). Using cognates as experimental materials in a language recognition task is not without its limitations, because cognates share orthographic features that would naturally lead to decreased accuracy in determining language of input. The results discussed here thus suggest that language source information is encoded for items in isolation, and to a lesser degree for items embedded in sentence contexts, the latter findings being dependent on items being studied in pure language lists. Nonetheless, the precise manner in which language source information is stored in memory has not been extensively investigated. The next section considers the main models of bilingual processing and grounds them in specific predictions for long-term memory retrieval of language source information.

\subsection{Bilingual Processing Models}

Although many models have been proposed to explain bilingual processing, three are central to discussing the issue of encoding language source information. The bilingual model of lexical access (BIMOLA; Grosjean, 1988) deals with how a bilingual recognizes words in

speech. The inhibitory control (IC; Green, 1998) model was proposed as a means of explaining how a bilingual deals with simultaneous input from both languages during task execution. Additionally, there is an attention and selection based account of bilingual processing that 
assumes selective language access. The two models of bilingual processing are complementary in nature but differ critically on whether they include language tags in their architecture. The spread-of-activation and language selective account of bilingual processing, the Costa model from here on (e.g., Costa \& Caramazza, 1999), differs in a number of respects from both these models, and models of word processing (e.g., the BIA+, Dijkstra \& van Heuven, 2002).

\subsubsection{Bilingual Model of Lexical Access (BIMOLA)}

The bilingual model of lexical access (BIMOLA; Grosjean, 1988; 1997; 1998) is a model that specifies how bilinguals recognize words presented auditorially. The BIMOLA organizes the acoustic signal into three levels (akin to the TRACE model in the monolingual speech perception literature; McClelland \& Elman, 1986). Features activate phonemes, which in turn activate words. When an acoustic stimulus is presented it activates relevant features, and the features activate phonemes. Once phonemes have been activated they exert inhibition to other phonemes in two ways. First, they inhibit phonemes of the irrelevant language, such that, for example, if an English phoneme is perceived, all irrelevant Spanish phonemes are inhibited. In this sense, phonemes are stored according to language, without language tags. Second, the phoneme activation leads to within-language inhibition such that irrelevant phonemes from the target language are inhibited as well. Ultimately, the target word is recognized.

The BIMOLA additionally assumes that a bilingual's languages are constantly activated and inhibited and that at any given moment, the bilingual has a base language. The base language is the one that is receiving more activation such that if you were to address the bilingual, they would expect to perceive acoustic information in the base language (Grosjean 2001; Grosjean \& Miller, 1994). Selection of the base language is based on a variety of factors including language dominance, the environment, and the characteristics of the speaker offering the acoustic input. In the BIMOLA, phonemes that are highly contrastive exhibit little cross-language competition, and that base language activation has an effect on phoneme perception (Bürki-Cohen, Grosjean, \& Miller, 1989). The BIMOLA does not specify language nodes, despite inhibition operating in a 
language-specific manner. Additionally, in the BIMOLA, phonemes from the irrelevant language are inhibited prior to word recognition. The BIMOLA does not specify how phoneme inhibition takes place in a language-specific manner, without overt language cues. Phonemes that share properties across languages are activated in parallel; however, as language specific phonemes are perceived, the non-target language receives overall inhibition. As more words are perceived in the target language, non-target language processing becomes more difficult (as in the case of guest words).

Two main findings provide support for the assumptions of the BIMOLA. First, with regard to auditory speech perception, bilinguals listen in a language selective manner when perceiving phonemes that are contrastive across languages (Bürki-Cohen, Grosjean, \& Miller, 1989). This finding provides support for the assumption that phonemes are stored by language, particularly those that are contrastive across languages. Indeed, Spivey and Marian (1999) found that when participants were presented with distractors that were phonetically similar across languages, they looked longer at the phonetically similar objects than the controls, suggesting that phonemes that are shared across languages are processed in a language non-selective manner. The BIMOLA can also account for this finding. Shared phonemes allow for language non-selectivity and as more phonemes are processed, relevant language candidates compete for selection. Second, bilinguals producing guest words appear to go in and out of the phonetic code for each language completely (Grosjean \& Miller, 1994). In studies where bilinguals produce code-switched words, the phonetic repertoire of the base language (the main language of interaction) appears to have no effect on the production of the phonetic properties of the codeswitched word. Thus bilingual code-switching involves a total switch between phonological codes. The auditory speech perception results suggest that there are some differences in processing words presented orthographically and auditorially. Bilinguals who are visually presented with a word appear to search the lexicon in a language non-selective way; however, when words are presented auditorially, a degree of constraint is placed on the search, in some instances producing a language-selective search. Language source distinctions may be more 
salient when perceiving auditory stimuli, particularly for bilinguals whose two languages share an alphabetic script.

\subsubsection{Inhibitory Control Model (IC)}

The IC model proposed by Green (1998) proposes a supervisory system that allocates processing resources according to task demands. The system is akin to the executive control system in that it constantly monitors information and allocates processing resources accordingly. The IC model has a supervisory attention system (SAS; Green, 1998; Norman \& Shallice, 1986) that operates by monitoring components of the language system according to specified task demands. The IC model proposes that language task schemas regulate any linguistic task; these schemas set goals that remain active until they are completed, or overridden by the SAS.

The issue of selection then, under the IC model, becomes one of inhibition of items that are inconsistent with task goals (Green, 1998). With regard to the language tag, or language source information, the IC model holds that language tags are essential to the performance of linguistic tasks. In order to appropriately select a lemma (abstract linguistic unit that contains the syntactic and semantic information about a word), and match it to its lexemic and graphemic representation (orthographic and phonological information about a word), candidates with the inappropriate language tag have to be suppressed (Green, 1998). At the lemma level, only lemmas with the appropriate language tag may operate. At the lexical level, however, lexical concepts in L1 may activate lemma-level information in L2, and lexical concepts in L2 likewise can activate lemma-level information in L1. The degree of cross-language activation between these levels of representation is dependent on task demands. Certain tasks (e.g., translation) require both lemmas to be active, or at least their lexemes or graphemes to be active, redundantly, until the task is completed (i.e. translation of the item has taken place). Hence, in the IC model, the function of the language tag is much more extensive than that expressed in the BIMOLA, recall that in the BIMOLA phonemes and words are stored by language without tags. The IC model posits that task demands specify how language information is accessed. Indeed, 
the IC model is the only model that specifies where language exerts influence, namely at the lemma level. In the IC model, the language tag guides selection, albeit in a non-selective system. Further, the language tag contributes important information as tasks and goals are completed. In essence then, the language tag is paramount to the suppression of irrelevant language source information.

Differential recovery patterns seen in bilingual aphasics suggests that language information is indeed tagged and stored by language, despite both systems interacting in typical bilinguals (Green, 2005). For example, some of the patterns of recovery after trauma include languages recovering in parallel, differentially, and one language recovering much more extensively than the other. In the particular case where following trauma, only one language

recovers, Green (2005) argues that the explanation for this particular pattern of recovery might be that the unrecovered language is in constant inhibition mode. That is, since we exercise control over which language to process, aphasics with this recovery pattern are unable to switch inhibition off for a particular language. This result is thus indicative of the fact that language cues indeed carry the strength necessary not only to inhibit but also to select and tag for language.

\subsubsection{Spread-of-Activation and Language Selective Account of Language Processing}

The most widely accepted model of bilingual word processing is the bilingual interactive activation plus (BIA+, Dijkstra \& van Heuven, 2002). In this model (as well as the models described earlier), bilinguals search the lexicon in a non-selective manner when perceiving words. That is, when identifying a word, candidates from both languages compete for selection at least in early stages of processing. One of the findings that support the idea of cross-language activation is that processing of cognates (words that share form and meaning across languages) is facilitated relative to controls. This finding has been extensively replicated in lexical decision (e.g., de Groot, Delmaar, \& Lupker, 2000; Dijkstra, Grainger, \& van Heuven, 1999) and reading (e.g., Libben \& Titone, 2009; Van Assche, Duyck, \& Hartsuiker, 2012) paradigms. However, 
several naming studies and a reevaluation of the idea that cognates are represented differently, by arguing that facilitation is observed because cognates receive more activation due to having shared semantic and phonological representations across languages, gave rise to a spread-ofactivation based account where processing is language-specific and based on the degree of activation of lexical entries in the target language (Costa \& Caramazza, 1999; Costa, Miozzo, \& Caramazza, 1999; Costa, Santesteban, \& Caño, 2005).

Costa's model (Costa et al., 1999) is based on stage models of word production in the monolingual picture naming literature. In these models, production of a word in response to a picture is the product of three discrete stages; the first is a semantic stage, the second a phonological stage, and the final stage is an articulatory buffering stage (Levelt, Schriefers, Meyer, Pechmann, Vorberg, \& Havinga, 1991). Similarly, for speech perception, discrete stages of lexical selection, phonological access to the target word, and semantic access, occurs in discrete non-overlapping stages (Levelt et al., 1991). In the bilingual instantiation of these accounts, word processing occurs in a language-selective manner, particularly for production tasks (e.g., Costa et al., 1999).

In this account, activation occurs for both languages through the semantic system and this activation allows lexical selection to occur. Selection of the target word in the target language leads to spreading activation of words in the non-target language. However, only words in the target language are candidates for selection. Evidence for this assumption comes from picture naming studies in which participants were presented with identical distractors (i.e., mesa for the target table) in the non-target language facilitated naming in the target language (Costa et al., 1999). These findings suggest that although semantic access spreads activation to the non-target language, language-selective processing allows only target words to become available for selection. If words in both languages were available for selection, interference of the identical distractor would have been observed.

Specifically for the production aspects of bilingual processing, Costa's model posits that only lexical nodes in the target language become available for selection. Lexeme 
(morphological) and lemma-level activation occurs in parallel at the lexical level according to this account (Costa \& Caramazza, 1999). Recall that in the IC, the language tag resides at the lemma level, and that this level exists somewhat independently at the lexical level. One of the critical aspects of the two models (Costa's and the IC) tested in the current studies is the issue of whether these representations are active to the same degree during different tasks, and whether it is lemma level engagement uniquely that leads to better language source retrieval.

\subsubsection{Memory Performance Predictions Based on Bilingual Processing Models}

As stated in prior sections, in terms of explaining bilingual phenomena, the BIMOLA and IC models are complementary in nature. One critical difference between these models is the emphasis they place on the language tag, or, using different terminology, on encoding of language source information. Language tags are virtually non-existent in the BIMOLA. That is, in the BIMOLA phonemes are stored by language, without language tags. In contrast, the IC model stresses the importance of tagging words for language. In order for the SAS (Green, 1998) to be able to monitor performance, it needs to know which linguistic items are relevant to performance. In order to speak, for example, one must somehow include information about which language is relevant in terms of the context. Given that language errors are relatively uncommon (Kroll \& Tokowicz, 2005), it appears that language tagging is a central part of the production process (La Heij, 2005). The process of speaking involves relatively late stages of processing and the findings are consistent with all three models. However, during the earlier stages of processing, where the BIMOLA operates without coding language below the phonological level, the IC model predicts that language source information acts as a filter. The IC model supposes that language source information is tagged during lexical access and continues exerting influence post-lexically (Green, 1998; La Heij, 2005).

Given the relative difference in strength attributed to language source information by the BIMOLA and IC models, and the fact that Costa's model assumes that lexeme and lemma-level information are activated to the same extent at the lexical level, we can begin to make 
predictions that contrast the three models and shed light on the effect of language source encoding on long-term memory. The IC model would predict a task-based influence on the strength of language source encoding, the locus of this strength being directly related to the level of lemma engagement of the encoding task. Tasks that are require stronger lemma engagement would presumably lead to stronger language source tagging. The lemma engagement position assumes that lemma-level information is somehow represented differently at the lexical level, in contrast to what Costa et al., (1999) argue in their model; if we assume that little to no tagging takes place during word recognition (a process that does not necessarily require lemma engagement), we would reasonably expect worse language source recollection when reading words than, for instance, when producing words. Further, the IC predicts that language cues are stored in the lexicon (at the lemma level), directly contrasting the assumption of language source information stored only at the phonological level without language tags in the BIMOLA. Therefore, it is logical to expect language source recognition to differ when words are studied auditorially than when they are studied in other modalities. The difference in predictions is particularly marked for early stages of processing. As processing unfolds on a time continuum, all models would predict similar performance given that lemma-level engagement becomes essential to the performance of the linguistic tag leading language source information to become more salient. The assumption of no explicit language tag for recognizing words auditorially in the BIMOLA leads to ambiguous predictions. The model is underspecified as to how phonemes from the irrelevant language are inhibited; the model assumes that phonemes are stored by language (thus allowing for non-target language inhibition); however, there are no overt language cues to guide phoneme selection. We can assume that phoneme storage by language is akin to a language tag. This assumption would lead to the prediction that language source information is readily available prior to word recognition, leading to strong episodic encoding of language source information, and retention of source language to the extent that phonological information about the episode is retained. However, semantic information is retained more 
reliably than phonological information in long-term memory (Baddeley, Papagno, \& Vallar, 1988; Becker, Moscovitch, Behrmann \& Joordens, 1997).

One way to test the predictions of these models is to test language source recognition by asking participants to encode verbal information and retrieve concepts. In such a paradigm, participants are not bound by orthographic or phonological information that cues responses at test. Additionally, one could use translation, a mechanism that forces language source encoding, and test whether these conditions lead to a stronger language source trace. The following sections detail bilingual performance in tasks ranging from lexical decision to auditory perception. Each section addresses significant findings and frames such findings within the larger theme of language source encoding. The final introductory sections address language constraints as well as word frequency and how these factors interact with source retrieval.

\subsection{Bilingual Evidence of Non-Selectivity in Lexical Decision and Sentence Processing}

In order to fully understand the cognitive architecture of the bilingual system, one must investigate processing at earlier, intermediate, and late stages. The lexical decision task has dominated investigations of early bilingual processing because it lends itself nicely to withinand across-language manipulations. In a basic lexical decision task, participants are asked to judge whether a letter string is a word or not. Lexical decision performance is thought to be representative of relatively early stages of processing because it involves discrimination judgments between items (de Groot, Borgwaldt, Bos, \& van den Eijnden, 2002), indeed it has been posited that word comprehension is not essential to performance in lexical decision tasks. An in-depth analysis of the lexical decision literature as it pertains to bilingual processing, specifically considering language source information, reveals how a bilingual's two languages behave and compete for selection very early on.

In order to explain the effects of bilingualism on lexical decision performance, I will address within-language lexical decision findings first, and global lexical decision findings second. This approach will be particularly useful as these findings are grounded in the larger 
perspective of language source encoding. There are several ways in which one can test whether a bilingual's languages interact during processing of items for lexical decision. One of the ways in which one can investigate whether both languages are active during processing, and how one ultimately selects a particular word, is to use words that share form, meaning, or both form and meaning across languages. Recall that words that share form and meaning across languages are called cognates. Words that share form, but not meaning across languages are called interlingual homographs or false friends. Finally, words that only share meaning across languages are called translation equivalents.

The overall consensus in the bilingual literature is that lexical access is non-selective with respect to language (e.g., de Groot, Delmaar, \& Lupker, 2000; Dijkstra, Grainger, \& van Heuven, 1999; Dijkstra, van Jaarsveld, \& Brinke, 1998). Evidence for this conclusion has been observed in the time it takes to perform lexical decisions on words that are cognates. Bilinguals respond to cognates more quickly than to non-cognate controls. The interpretation of this finding has been that cognates have a special status; the fact that they exist in similar forms across languages makes it easier to decide that the letter sequence is indeed a word (e.g., de Groot, Delmaar, \& Lupker, 2000; Dijkstra, Grainger, \& van Heuven, 1999; Dijkstra, Miwa, Brummelhuis, Sappelli, \& Baayen, 2010). Interlingual homographs share orthography and/or phonology but not meaning across languages. In within-language lexical decision paradigms, bilinguals respond to interlingual homographs more slowly than to matched control words (de Groot, Delmaar, \& Lupker, 2000; but see Dijstra, van Jaarsveld \& Brinke, 1999, for nonsignificant differences between interlexical homographs and control words). The interpretation of the latter finding is that cross-language competition arises between words in a bilingual's two languages and the resolution of this competition leads to a lag in reaction time (de Groot, Delmaar, \& Lupker, 2000; Dijkstra, Grainger, \& van Heuven, 1999; Dijkstra \& van Heuven, 2002). However, when participants are asked to perform a global lexical decision task where they respond positively to words from both languages, cognate facilitation is observed, but inhibition for interlingual homographs is eliminated (Dijkstra, Grainger, \& van Heuven, 1999). 
The previous section detailed how bilinguals process words that share linguistic features across languages. Cognates, words that share form and meaning, were consistently facilitated. Interlingual homographs, words that do not share meaning across languages, led to inhibition or null effects depending on task instructions. However, bilinguals rarely encounter information outside of a meaningful context, and it is necessary to understand how their languages interact while processing items in a linguistic context. The following overview of the literature on bilingual sentence processing is by no means exhaustive and is grounded within the larger context of language source information. Specifically, the effects on lexical access of items embedded in sentence contexts will be addressed as well as the processing of ambiguous words.

Several studies have found facilitated processing for cognates embedded in sentences (e.g., Libben \& Titone, 2009; Schwartz \& Kroll, 2006; van Hell \& de Groot, 2008). The facilitation effect however is dependent on the degree of semantic constraint of the sentence (Schwartz \& Kroll, 2006; van Hell \& de Groot, 2008). That is, a sentence that is highly constrained, semantically, will reduce the size of the facilitative effect of the cognate relative to a sentence that is not highly semantically constrained. Early processing measures, namely first fixation duration (how long one spends on a word, at first encounter, before moving on), suggest that cognates are facilitated during early processing, but this effect diminishes in later processing measures like total reading time (Libben \& Titone, 2009; Van Assche, Duyck, \& Hartsuiker, 2012; but see Van Assche, Drieghe, Duyck, Welvaert, \& Hartsuiker, 2011). Indeed, evidence suggests that a sentential context reduces the degree of cross-language activation across orthographic and, to a lesser extent, semantic domains (Schwartz \& Arêas da Luz Fontes, 2008). These effects suggest that the very large facilitation effects observed in single word recognition are a function of encountering words outside of a meaningful context and being able to devote all processing resources to that individual item.

The studies described so far have accounted for individual word processes within the larger context of a sentence. It appears that early bottom-up processes are non-selective (Libben \& Titone, 2009) with respect to language, and that later top-down processes are, to a certain 
extent, influenced by cross-language activity (Van Assche, et al., 2011). Further, it appears that a bilingual's two languages are integrated at the syntactic level, suggesting they affect each other at both the individual word level, but also the broader sentence processing level (Dussias \& Cramer Scaltz, 2008; Hartsuiker \& Pickering, 2008). Indeed, bilingual recognition memory experiments demonstrate that the episodic availability of individual items decreases once they are embedded in a sentence context, even in conditions where sentences had to be translated at study (Strobach, Francis, Perea, \& Motta, 2013).

The research findings discussed as it pertains bilingual sentence processing indicate that languages are active, and competing for selection both at the individual word-recognition level, and at later integration stages of reading. In terms of language source information, the crosslanguage activation and competition results highlight the importance of understanding how language source information is transferred into long-term memory. The lexical decision literature, and the sentence context literature provide a broader understanding of passive bilingual processing of information. Now the focus will shift to bilingual production of their two languages.

\subsection{Bilingual Production Performance}

Lexical decision paradigms and sentence processing findings suggest that a bilingual's cognitive architecture allows for certain processing advantages for words that share form and meaning across languages. Likewise, storage of items that share only orthography, allows for more flexible access to multiple meanings. Both lexical decision and reading are tasks that tap into recognition processes; an item is presented either in isolation or in context and the bilingual has to, at the very least, recognize the item as a word that they know. In a sense, the search to be conducted is limited to the orthographic form of the items and /or the tasks demands. Theoretically, you could recognize or read a word for which you do not have a conceptual representation. Tasks that are productive in nature are more likely to require conceptual access. The following section will detail findings on how bilinguals produce items, both in experimental 
settings and in settings that reflect natural language use. The word naming, picture naming, tipof-the-tongue, translation, and code-switching findings have spurred much debate about the processes involved when a bilingual seeks to produce items in their L1 and their L2. The following sections will consider findings from these varied production processes and how they relate to language source information.

\subsubsection{Word Naming, Picture Naming, and Tip-of-the-tongue States}

The process of word naming involves processing an orthographic stimulus, accessing its phonology, and producing it. The main finding in naming experiments is that bilinguals take longer to name words than their monolingual counterparts (e.g., Meuter \& Allport, 1999). The finding that bilinguals are slower to name items than monolinguals naturally leads to the question of whether there is a difference in word naming in the L1 and the L2. Indeed, bilinguals are generally slower to name words in L2 than in L1 (e.g., Kroll \& Stewart, 1994). However, in bilingual experiments where words are named in both languages, a switch cost is observed when switching to the L1 (e.g., Kroll, Bobb, Misra, \& Guo, 2008; Meuter \& Allport, 1999). By some estimates, switching to the L1 takes almost twice as long as switching into the L2 (Meuter, 2005). An explanation for the switch cost observed when switching into the L1 is known as the inhibition hypothesis (Kroll, Bobb, Misra, \& Guo, 2008). According to this view, the requirements to use the target language necessitate inhibition of the non-target language, which in turn leads to naming delays when the language changes. The inhibition hypothesis is consistent with the idea of strong traces for language tags and language source information. In essence, in order to produce an item, a bilingual inhibits by tag (i.e., irrelevant items are inhibited in order to allow production of relevant items). The inhibition hypothesis also postulates that it is more effortful to inhibit the dominant language; therefore, the switch costs observed when switching to the L1 are due mostly to the effort it takes to make L1 items available for selection (Kroll et al., 2008). This inhibition effect is not due to the fact that L1 words take longer to name, in fact, L1 words are named significantly faster than L2 words (Kroll \& Stewart, 1994). 
Inhibition is further observed when items share orthography across languages but are realized differently, phonologically (Jared \& Kroll, 2001). The cost of switching however is attenuated or eliminated in bilinguals who are highly proficient in both languages (Meuter, 2005; Meuter \& Allport, 1999). Indeed, when participants report extensive use of their L2, the switch cost is reversed (Meuter, 2001, as cited in Meuter, 2005). The switch cost is indicative of a tagging mechanism for which unhibiting the dominant language is more costly because more effort is required to inhibit it.

In addition to naming orthographic stimuli, for which the stimulus to be named is presented on the screen, we can investigate production processes by having participants generate words. In such experiments, participants are given a category or a cue and asked to generate one or more relevant words. When participants are given a conceptually-driven encoding task in language $\mathrm{A}$, and then asked to generate as many items in a specific category in language $\mathrm{B}$, there is significant between-language priming (Francis, Fernandez, \& Bjork, 2011), leading participants to generate translations of the items presented at study. Cross-language priming effects during production have been observed for both nouns and verbs (de la Riva López, Francis, \& García, 2012; Francis, Férnandez, \& Bjork, 2011). These cross-language priming effects suggest that conceptual access is shared across languages (de la Riva López et al., 2012). The results also suggest that when a concept is accessed, both translation equivalents receive activation, albeit to a lesser degree in the non-target language. The shared conceptual representation of translation equivalents is incorporated into the major models of bilingual processing

Thus far, the production findings have been limited to performance when orthographic cues are present, or when generation restrictions are placed. In addition to producing items by accessing conceptual information, often people access conceptual information first, and then plan to produce a word. Such processing is examined when bilinguals name pictures. The process of picture naming entails processing the visual stimuli, accessing its conceptual representation, activating the lexical item(s) that name it, and, in the case of bilinguals, selecting the appropriate 
lexical entry contingent upon context or task demands (Michael \& Gollan, 2005). In experiments on repetition priming in picture naming, naming the picture in language A at first exposure primes naming of the same picture in language B in subsequent presentations (Francis, Augustini, \& Sáenz, 2003; Francis, Corral, Jones, \& Sáenz, 2008); that is, translation equivalents are primed. Recall that the same finding is observed in category exemplar generation as described previously. These results indicate that translation equivalents have shared conceptual representations. Further, in experiments where a distractor word is presented during picture naming, participants perform differentially depending on the type of distractor. For instance, if the distractor is the translation of the target item, naming is facilitated (e.g., Costa, Miozzo, \& Caramazza, 1999). Instead, when the distractor is phonologically similar to the translation, but differs in meaning, naming is delayed (e.g., Hermans, Bongaerts, De Bot, \& Schreuder, 1998). The finding that items in the non-target language affect naming suggest that both languages are active even at later production stages when lexical access is hypothesized to have already taken place and that inhibition or suppression of the non-target language occurs even as one plans a speech output, presumably in the target language (Kroll et al., 2008). Indeed, if competition arises at the production stage, language tags would be instrumental in our ability to perform any given language task (Green, 1998).

The evidence discussed so far in this section has restricted the search for items that bilinguals must produce. A naturally occurring phenomenon that affects both bilinguals and monolinguals alike is the tip-of-the-tongue state. Tip-of-the-tongue (TOT) states are typically characterized as failures to retrieve a word that is known (Gollan \& Acenas, 2004; Michael \& Gollan, 2005). Bilinguals consistently have more TOT states than monolinguals, irrespective of whether they are attempting to retrieve an item in the L1 or the L2 (Michael \& Gollan, 2005). The two instances where TOT states are reduced is when bilinguals are trying to retrieve cognate items, or when retrieving the translation of the target is possible (Gollan \& Acenas, 2004; Michael \& Gollan, 2005). The fact that bilinguals experience more TOTs has been explained by taking a weaker links position. The weaker links hypothesis states that each individual word is 
encountered less frequently in routine exposures for bilinguals than it would be for monolinguals, therefore each word is more weakly associated to its conceptual representation leading to a lag in production time (e.g., Gollan, Montoya, Cera, \& Sandoval, 2008; Gollan \& Silvenberg, 2001; Michael \& Gollan, 2005), as well as making items more susceptible to a TOT state (Gollan \& Acenas, 2004). In addition to explaining TOT state phenomena, the weaker links view explains quite nicely why it is that items processed in a bilingual domain often behave as lower frequency items (Michael \& Gollan, 2005), irrespective of the base frequency in the language to which they belong. An L2 item has even fewer lifetime exposures and therefore is associated even more weakly to its underlying concept than an L1 item would (Gollan et al., 2008). The weaker links hypothesis then allows us to understand certain word and picture naming phenomena, as well as why bilinguals experience more TOT states than monolinguals. Nonetheless, while it would appear that bilinguals are more susceptible to falling into a TOT state, it is the experience of bilingualism that can also facilitate retrieving the TOT item. The TOT literature provides further evidence of the fact that a bilingual's two languages are always active. The issue of selection then becomes one of investigating how languages get selected, and further, how a particular language's information (i.e., saying that an item belongs to English), gets encoded into long-term memory.

The production literature covered so far suggests several things about bilingual production. First, bilinguals have more words available for production, considering vocabulary in both languages, which means that each word has had less lifetime exposures, and this in turn leads to longer naming latencies and a greater incidence of TOT states. Second, bilinguals engage in constant suppression when producing items, this suppression is particularly strong for the L1, where robust switch costs are observed, and these switch costs are attenuated by proficiency (Meuter, 2005). Third, there is cross-language priming when generating items, but also when accessing an item's conceptual representation (i.e., by naming pictures). Fourth, while there is cross-language priming and facilitation for certain items, there is also cross-language interference when items share phonology but not semantics. Taken together, these findings 
provide an overall picture that suggests that items in the bilingual lexicon are somehow organized by language. This language source organization allows for inhibition, competition, and facilitation. What remains unknown is whether an episodic encounter with an item from the bilingual lexicon is likely to be tagged by language given that, at some level, language source information exists. The following production sections will review targeted language source switches (translation) and targeted contextual language switches (code-switches). Both translation and code-switching involve a deliberate attempt at retrieving an item in another language.

\subsubsection{Translation and Code-Switching}

In previous sections, processing has been described in terms of how a bilingual's two languages play a role during any given task. Overwhelmingly what has been found is that both languages are active and competing for selection, and selection of the appropriate language requires inhibition or suppression, and monitoring, of the non-target language. Prior sections have dealt predominantly with tasks that require use of one language; even naming tasks that require switching require only one language to be active at any given moment. There are tasks, however, that require both languages to be active simultaneously. One such task is translation; translation requires finding the translation equivalent in the non-target language, for any given item in the target language. Translation therefore requires the lexical entry for any given concept to be active in both languages. Another task that requires activation of both languages is codeswitching. Code-switches are introductions of items from the non-target language into target language discourse (Myers-Scotton, 2005). Code-switching requires the non-target language to be actively processed such that at any given moment, an item can be retrieved and introduced into target language discourse. Translation is a naturalistic event that occurs routinely for bilinguals. Some bilinguals do not code-switch (La Heij, 2005) for reasons other than proficiency; however, bilinguals who code-switch do so often. 
Concept-mediated translation involves accessing the word form of the presented word, accessing its conceptual representation, and then finding the word form for the same concept in another language (e.g., Kroll \& Stewart, 1994). Further, concepts for translation equivalents are, at least to a certain extent, shared (e.g., de la Riva López, et al., 2012; Francis, 1999; Francis et al., 2011; Kroll \& Stewart, 1994), and activation of translation equivalents occurs during incidental processing (when the task has nothing to do with translation or language processing in general; Wu, Cristino, Leek, \& Thierry, 2013; Wu \& Thierry, 2012). The revised hierarchical model (Kroll \& Stewart, 1994) makes predictions about how lexical and conceptual information is stored in the bilingual lexicon; in turn this organization affects how bilinguals translate items. Bilinguals who are markedly more fluent in the L1 than the L2 are more reliant on conceptual links when translating from the L1 to the L2; translating from the $\mathrm{L} 2$ to the $\mathrm{L} 1$ is contingent upon lexical links between the two languages (Kroll \& Stewart, 1994; Kroll et al., 2010). The different sources of information that are relied upon when translating from the L1 to the L2 and vice versa lead to a translation asymmetry, where translating from the L1 to the L2 is slower than translating from the L2 to the L1 (e.g., Kroll \& Stewart, 1994). Another explanation for the translation asymmetry stems from experiments that suggest that for these bilinguals, the asymmetry in production is larger than the asymmetry in comprehension (Francis et al., 2005). The asymmetry observed in bilinguals for whom the L1 is much more dominant than the L2 is virtually eliminated when bilinguals are highly proficient in both languages (e.g., Francis et al., 2003; Francis \& Gallard, 2005; Francis, Tokowicz, \& Kroll, 2014).

Processing an item for which a translation is known activates information about the translation equivalent. For instance, in lexical decision paradigms, presenting a word speeds lexical decision for a translation equivalent presented immediately afterwards (Altarriba, 1992; Frenck-Mestre \& Vaid, 1992; Gollan, Forster, \& Frost, 1997), suggesting that when an item is processed, its translation equivalent gets activated as well. This effect however is short lived. Indeed, no cross-language priming is observed after a delay (e.g., Durgunoglu \& Roediger, 1987). However, not all translation equivalents are processed equally, items with many 
translation equivalents are translated slower and less accurately (Broada, Sánchez-Casas, Gavilán, García-Albea, \& Tokowicz, 2013), suggesting that processing for some translation equivalents is easier than for others. Translation equivalents can be useful for bilinguals experiencing TOTs; when bilinguals are stuck in a TOT state, knowing the translation of the TOT item helps resolve the TOT state (Michael \& Gollan, 2005). The overall pattern of results when considering translation equivalents suggests that languages are highly interactive, and that the co-activation of both languages can be a source of facilitation during production.

Translation is not always seamless, however. In Stroop-like translation experiments, distractor items in the target language of translation that share meaning with the target item produce a Stroop-like interference effect. Items in the target language that share form with the target item produce facilitation (Miller \& Kroll, 2002). The pattern is significantly attenuated when the items are presented in the non-target language of translation (i.e., in the same language as the item that is to be translated). These results show that while languages are highly interactive at late production stages, there is a mechanism of language selection that allows for translation to take place.

Bilingual translation involves a willed search into the lexicon for an equivalent in another language. In some ways, translation is akin to the process of finding a synonym in the monolingual domain. However, translation involves accessing the word form representation for both languages that share the same concept. In addition to translation, bilinguals engage in other contact phenomena, code-switching. Code-switches are intentional and deliberate introductions from the non-target language into target language discourse (La Heij, 2005; Myers-Scotton, 2005). For example, a speaker who is contextually required to speak Spanish might say La escuela estaba llena de kids. Code-switching thus involves continuous monitoring of both languages, subsequently retrieving the non-target language item, then inserting the item in the context of the target language. When code-switches occur, they are structurally and syntactically correct (Myers-Scotton, 2005), that is, the item from the non-target language does not violate the 
syntactic constraints of the target language. Further, code-switches are only performed with speakers for whom a code-switch is judged to be appropriate (La Heij, 2005).

Code-switching is a process that involves keeping track of language source information. In fact, studies have shown that bilinguals are unconsciously aware of language source information (Chauncey, Grainger, \& Holcomb, 2008). In priming experiments, where the task is unrelated to language (e.g., categorization), where prime items are presented at very short SOAs, participants show differential priming effects for their L1 and their L2. Switches from the L1 elicit a later priming effect (N400 component) while switches from their L2 elicit an earlier priming effect (at the N250 component) (Chauncey et al., 2008), suggesting that monitoring of information occurs relatively early during comprehension. Although code-switching is thought to be cognitively costly (e.g., Altarriba, Kroll, Sholl, \& Rayner; 1996; Macnamara \& Kushnir, 1971), it can be facilitative relative to choosing a within-language synonym (Moreno, Federmeier, \& Kutas, 2002). That is, cognitively speaking, it is more efficient to process a codeswitched item than it is to process a lexical within-language synonym of an expected target word.

The evidence from translation and code-switching suggests that bilingual speakers are very efficient at keeping track of their two languages, despite operating largely in a non-selective manner. The evidence in this section further shows that processing of a bilingual's L1 and L2 is not the same. In translation for instance, there is an asymmetry observed for unbalanced bilinguals. Similarly, for code-switching, there appears to be a processing difference between the L1 and the L2. The fact that differences in processing and production are observed for the L1 and the L2, despite both items existing in a unified lexicon, provides further evidence that suggests that the language source of these items might be represented distinctly in episodic memory. Translation and code-switching allow contact between two languages that have entirely different rule systems dealing with their phonology, and syntax. The next section deals with how bilinguals master dealing with two phonologically different languages. 


\subsection{Bilingual Auditory Speech Perception}

Prior sections dealt with how bilinguals process orthographic stimuli. For some bilinguals, their two languages share the same script (i.e., English and Spanish both have an alphabetic writing system). Some bilinguals however have two different systems that govern their written languages. Thus, the way bilinguals process written words will differ at least in some respects from the way they perceive their language(s) phonologically. Developmentally, children acquire a language's phonological features prior to semantic mapping and certainly before orthography. Indeed, there is evidence that phonological learning occurs in-utero (Moon, Lagercrantz, \& Kuhl, 2013), and that bilingual newborns are able to differentiate between two languages if both were spoken routinely while the infant was in the womb (Byers-Heinlein, Burns, \& Werker, 2010). Even as infants, bilinguals perceive their two language systems as being fundamentally different (Sebastián-Gallés, Albareda-Castellot, Weikum, \& Werker, 2012). Indeed, while acquiring the important phonological contrasts of their languages, bilingual infants remain flexible when perceiving phonemic distinctions. Monolingual infants typically commit to the phonemic contrasts of their native language by 6-months (Kuhl, Williams, Lacerda, Stevens, \& Lindblom, 1992; Werker \& Tees, 1984), bilingual infants however do not show this commitment until about 10-months of age (Kuhl, Tsao, \& Liu, 2003). In essence, the experience of bilingualism allows for some flexibility in acoustic perception given that two phonological systems are being mastered.

Adult bilingual hearers also show a language-specific commitment to one of their languages when perceiving language-specific phonemes (Bürki-Cohen, Grosjean, \& Miller, 1989). That is, when perceiving a sound that is relevant to only one of their languages, bilinguals show a commitment to process that language selectively. However, non-selective perception is observed when phonemes are shared across languages (Spivey \& Marian, 1999). One particular line of research suggests that bilinguals are constantly moving between language modes. Proponents of the language mode approach suggest that bilingualism is experienced in a continuum where on the one hand a bilingual can be in a monolingual state (in either of their 
languages) and on the other hand, the bilingual can have co-activation of both languages (at varying degrees; Grosjean, 1997). The language mode will thus dictate how phonetic stimuli are perceived. For instance, in a monolingual mode, any phonetic input will be perceived according to the rules of the language that is active. In a bilingual language mode, the incoming acoustic signal will be processed in a language non-selective manner, or alternatively, according to the base language. The base language is in turn selected on the basis of dominance and/or cues from the environment (such as the type of speaker providing input).

One of the ways of investigating how bilinguals perceive the phonetic features of their languages is to present them with code-switches. In such paradigms participants listen to either mixed language word lists, or mixed language sentences. When participants expect the information to be presented in one language exclusively, there is a cost associated with processing a code-switched word (Grosjean, 1988), suggesting that phonetic perception is language specific. However, the way in which bilinguals process auditory stimuli depends on several intrinsic and extrinsic factors including fluency, degree of activation of a bilingual's two (or more) languages, word properties, and phonotactic constraints (Grosjean, 1997). The evidence presented thus far thus does not show a clear picture of phonetic perception in bilinguals. Some paradigms support a language selective mechanism for perceiving phonetic input, and others support a language non-selective mechanism. Considering the language mode proposal the answer may lie in the resting level of activation of a bilingual's two languages. Whether phoneme perception occurs in a selective or non-selective manner has implications for language source encoding. Specifically, if bilinguals perceive certain units (e.g., contrastive phonemes) selectively, then it is likely that language membership information plays an important role during lexical access of auditory stimuli. Likewise, if the phoneme perception system is nonselective in nature, then the role of language membership or source information is unlikely to be significant. A third possibility is the notion of the language mode, this possibility would vary the strength of encoding of language source information within each bilingual such that at any given time phoneme perception could operate in a language selective, or non-selective manner. Given 
that phonological awareness is to a certain extent constrained by the rules of a particular language, the next section will detail how bilinguals deal with two or more sets of language constraints.

\subsection{Phonotactic and Syntactic Constraints on Language Access and Selection}

Language processing and selection of the elements in a particular language is guided by a set of rules that are unique to each language. Specifically, as it pertains to phonological processing, languages have an established set of rules that dictate how words are to be constructed, these rules are known as phonotactic constraints. Phonotactic constraints limit the types and clusters of sounds that ultimately form words (Amastae, in preparation). For example, in English, str- is a permissible word onset cluster; this cluster is violative however of the phonotactic constraints of Spanish. A bilingual then has, essentially, two sets of phonotactic constraints.

The degree to which each set of phonotactic constraints in a bilingual's lexicon impacts performance on either language depends on whether the participant is judging items explicitly or implicitly. In a series of studies with English-German bilinguals, Altenberg and Smith Cairns (1983) found differences in the degree of overlap of phonotactic constraints when participants rated the acceptability of words as opposed to when they performed a lexical decision task. Specifically, participants were shown items that violated English phonotactic constraints, but were acceptable nonword constructions in German, and vice versa. Additionally, participants were presented with items that violated constraints for both, or for neither language. When participants overtly rated the items, there was no interference of the non-target language's phonotactic constraints. When participants performed the lexical decision task, there was influence from the non-target language's set of phonotactic constraints. Namely, participants were slower at rejecting items that were permissible in the language that was irrelevant to the task (Altenberg \& Smith Cairns, 1983). 
Further evidence of the influence of phonological and phonotactic information on language processing is observed when bilinguals are presented with a word that is orthographically the same but phonologically realized differently across languages, such words take longer to name (Jared \& Kroll, 2001). Further, a word is named slower if its cross-language neighborhood density (words that look like the target word) is larger in the non-target language (Dijkstra, 2009). At first glance these findings might suggest that language source information doesn't prevent non-selectivity and intrusion from the non-target language and thus is not an impactful organization tool during processing. After all, if language source information were playing an important role during processing of phonologically ambiguous words, or words with higher neighborhood densities in the non-target language, shouldn't it prevent the non-target language from interfering in a language exclusive task? To a certain extent, language source information should inhibit all inappropriate lemmas. However, if we take an inhibition perspective, perhaps the phonological code of the inhibited lemma is still receiving activation via the shared orthography or phonology of the items. Therefore, although there is competition to be resolved, it is ultimately language source information that determines the appropriate response.

In addition to phonotactic constraints, languages follow a set of syntactic rules. Syntactic rules dictate how items may appear in a sentential context. The degree of cross-language activation and competition for individual items depends on the degree of semantic constraint placed on their surrounding context (Schwartz \& Kroll, 2006). That is, there is a reduction in semantic influence from the non-target language in sentences that are highly constrained, semantically, in the target language. Specifically, Schwartz and Kroll (2006) found that cognate facilitation was practically eliminated in sentences that were highly semantically constrained. To a certain extent this finding indicates that a syntactic context aids participants with language selection. If cognates receive an additional boost of activation, and show facilitative effects at recognition (e.g., de Groot, Delmaar, \& Lupker, 2000; Dijkstra, Grainger, \& van Heuven, 1999), and the findings in Schwartz and Kroll (2006; but see Libben \& Titone, 2009, for early lexical access in high constraint sentences) suggest that this effect is attenuated when the surrounding 
context is highly constrained, then it follows that a sentential context allows for language source information to reduce the degree of availability of the competing language.

Within the context of language source information, it would appear that when participants are presented with a string of letters, both sets of rules are active and available for selection. However, when participants are constrained either phonologically or syntactically, they are much more likely to select the constraints of the target language. The final consideration that played a role as these studies were designed was whether word characteristics play a role in language source retrieval. One particular word characteristic that has been extensively studied both in terms of processing and episodic retrieval is word-frequency. Word-frequency refers to the overall frequency with which a word occurs in a language. The following section details frequency effects both in terms of processing and memory performance.

\subsection{Word Frequency Effects on Performance}

Word-frequency effects have been found in a variety of domains from lexical processing to memory retrieval. In the bilingual domain, as in the monolingual domain, lexical processing is faster for high-frequency words (Duyck, Vanderelst, Desmet, \& Hartsuiker, 2008). In terms of organization of items by language, the L2 seems to be of lower overall frequency than the L1. In lexical decision paradigms, word recognition is slower for the L2 than it is for the L1 (e.g., Duyck et al., 2008), and in semantic classification paradigms, word comprehension is slower for the L2 than for the L1 (e.g., Francis \& Goldmann, 2011). Similarly, in production, L2 picture naming is slower than L1 production (e.g., Potter et al., 1984). Bilingual theories of language organization argue that, particularly when the L2 is acquired late, it follows a learning trajectory where each item will be of a lesser frequency relative to items in the L1, because each item in the L2 is encountered less often than items in the L1 (Duyck et al., 2008; Gollan et al., 2008). Recall memory is better for high-frequency words (e.g., Durgunoglu \& Roediger, 1987; MacLeod \& Kampe, 1996) and for L1 words (e.g., Durgunoglu \& Roediger, 1987). Recognition memory is better for low-frequency words (e.g., Francis \& Strobach, 2013; MacLeod \& Kampe, 1996) and 
for L2 words (Francis \& Gutiérrez, 2012; Francis \& Strobach, 2013). The low-frequency and L2 advantages in recognition memory are explained by the source-of-activation-confusion theory, which states that low-frequency words are associated with fewer episodic exposures than highfrequency words and are therefore more accurately recognized as being experienced experimentally (Diana \& Reder, 2006). Similarly, L2 words are associated with fewer episodic exposures than L1 words and are therefore more accurately recognized (Francis \& Strobach, 2013). The pattern of results for how word frequency affects word recognition processes and memory processes suggests that word-frequency plays a large role in language processing as well as in memory processing. Specifically, when considering language source information in the proposed experiments, it appears, at least from the recognition literature, that lower frequency items might be more salient at retrieval thus leading to better language source discrimination. One of the purposes of the proposed studies is to empirically test the influence of wordfrequency on language source recognition.

\subsection{The Present Studies}

The present experiments investigate how language source information is encoded into long-term memory. Across five experiments, different encoding demands were placed on participants when memorizing high- and low-frequency words in their two languages. Experiment 1 tested how language source information is encoded when words are presented visually. Experiment 2 tested language source encoding when words were embedded in a sentence. Together, Experiments 1 and 2 provided evidence for how language source information is encoded when presented visually as a function of the frequency of the words memorized. Experiment 3 tested encoding of language source information after a production task at study. Experiment 4 tested encoding of language source information after auditory word presentation. Experiments 3 and 4 address language source retention as a function of productive and receptive processes and how these processes were affected by word frequency. Further, the encoding tasks in Experiments 1 and 4 are perceptually based, and the encoding task in Experiment 3 is 
conceptually based; the comparison of these three experiments sheds light on whether perceptual or conceptual processes lead to better retention of language source information. Finally, Experiment 5 investigated whether language source information is available when processing words in both languages and whether word frequency benefits retrieval in a bilingual task. In order to be able to make cross-experimental comparisons, participants were randomly assigned to experiments.

In addition to investigating the effects of encoding task, one of the aims of this dissertation was to bridge the gaps in knowledge between the bilingual and memory literatures. One consistent source of debate in the bilingual field is whether at any point in processing, the bilingual is able to process incoming linguistic stimuli in a non-selective manner. Certain studies that take into account task demands have found that indeed, participants are able to shift their language 'mode' to more heavily rely on one of their languages (Elston-Güttler, Gunter, \& Kotz, 2005). In an effort to recreate this finding in this series of experiments, we manipulated language of instruction to participants. If indeed language 'mode' is related to and affects language source encoding, then hearing instructions exclusively in English or exclusively in Spanish should have an effect on the language source discrimination decision. We predicted that if language source encoding was affected by language of instruction, this effect would be evident not only in the discrimination decision itself but in participants showing a bias to select one language over the other. That is, if the instructions were exclusively in English, then there would be a bias to select English as the source language of the words.

The manipulations of word-frequency, encoding task and language of instruction were designed to test several hypotheses, each of which leads to specific predictions.

Hypothesis 1: Source retrieval is more accurate for episodically distinct items. This hypothesis leads to the prediction that there will be a discrimination advantage for low-frequency words across all experiments. 
Hypothesis 2: Source retrieval is more accurate for items subjected to more effortful processing. This hypothesis leads to the prediction of a clear and significant advantage for producing words relative to comprehending them.

Hypothesis 3: Language tagging occurs at relatively early stages of lexical processing. This hypothesis leads to the prediction that discrimination will be better for words studied in isolation than words studied in a sentence context.

Hypothesis 4: The auditory system is more attuned to language tags and more efficient at language selection. This hypothesis leads to the prediction that the language source of words studied auditorially will be more easily discriminated than the language source of words that were read at study.

Hypothesis 5: Production processes rely more heavily on language tagging than comprehension processes. This hypothesis leads to the prediction that the language source of words that were produced will be more easily discriminated than the language source of words that were comprehended.

Hypothesis 6: Languages in contact create language source confusion. This hypothesis leads to the prediction that translating words will lead to poor language source discrimination relative to reading and producing words.

Hypothesis 7: Bilinguals shift their language 'mode' to suit task demands. This hypothesis leads to the prediction that manipulating language of instruction will lead to differences in discrimination and bias to classify a word as having been presented in the language of instruction rather than the other language. 


\section{Chapter 2: Experiment 1}

Experiment 1 tested the basic hypothesis that source retrieval is more accurate for episodically distinct items. Participants memorized a mixed list of English and Spanish words. Subsequently, at test, participants were shown a sequence of pictures and indicated whether the word that named each picture originally appeared in English or Spanish during the study phase. Half of the words were high frequency, and half of the words were low frequency, with equal numbers of high- and low-frequency words for English and Spanish. Additionally, language of instruction was manipulated. Participants were randomly assigned to receive either exclusively English or exclusively Spanish instructions for the entire experimental protocol.

\subsection{Method}

\subsubsection{Participants}

Forty English-Spanish bilinguals (25 women, 15 men) were recruited from the introductory psychology participant pool at the University of Texas at El Paso. Objective proficiency measures obtained from the WMLS-R determined that 22 participants were English dominant and 18 were Spanish dominant, and all but one participant reported learning Spanish prior to English. (Summary information on participants is presented in Table 1). Students were given course credit for their participation.

\subsubsection{Materials}

Language Background Questionnaire. Participants completed the ESPADA (EnglishSpanish Proficiency and Dominance Assessment, Francis \& Strobach, 2013a), a self-report questionnaire on their use of language. The questionnaire contains items that assess proficiency levels, frequency of use, and age of acquisition information for both English and Spanish.

Woodcock-Muñoz Language Survey Revised (WMLS-R NU). The Woodcock-Muñoz Language Survey Revised (Woodcock, Muñoz, Sandoval, \& Alvarado, 2005) is a standardized battery of tests that is used to assess proficiency in English and Spanish. Scores on Tests 1 
through 4, which include picture naming, verbal analogies, word identification and dictation tasks, have been used in prior research to determine language dominance (e.g., Francis \& Strobach, 2013). Test 1 alone has also been used in prior research to determine the bilingual status of participants (Strobach, et al., 2013); however, it is likely that picture naming alone is insufficient to determine proficiency. Therefore, in the present study, both Test 1 (picture naming) and Test 2 (verbal analogies) were administered to determine language dominance. Bilingual proficiency was assessed by looking at the relative proficiency index for oral language for both English and Spanish. The RPI is an index that assigns a percent score to a participant given that the native monolingual speaker of that language scores 90 percent. In order to complete the study, participants had to score at least a 35/90 for both English and Spanish.

Table 1.1: Participant Language Characteristics

\section{Experiment}

\begin{tabular}{|c|c|c|c|c|c|}
\hline Characteristic & 1 & 2 & 3 & 4 & 5 \\
\hline Age & 20.7 & 21.2 & 20.7 & 20.5 & 20.6 \\
\hline AoA English & 6.4 & 6.3 & 6.8 & 6.1 & 6.4 \\
\hline AoA Spanish & 1.7 & 2 & 1.6 & 1.6 & 1.6 \\
\hline AE Englishii & 15.4 & 18.0 & 16.2 & 22.3 & 16.1 \\
\hline AE Spanish & 15.8 & 16.0 & 15.2 & 14.8 & 15.3 \\
\hline English Dominant & 22 & 23 & 28 & 26 & 22 \\
\hline \multicolumn{6}{|l|}{$\mathbf{N}^{\mathrm{iii}}$} \\
\hline Spanish Dominant N & 18 & 17 & 12 & 14 & 18 \\
\hline \%Speak English ${ }^{\text {iv }}$ & 44.56 & 56.54 & 46.75 & 47.76 & 49.51 \\
\hline \%Speak Spanish & 38.32 & 31.56 & 43.20 & 35.63 & 29.65 \\
\hline \% Speak Mixture & 17.12 & 11.90 & 10.05 & 16.61 & 20.84 \\
\hline Eng Reading ${ }^{v}$ & 8.57 & 9.23 & 8.63 & 8.68 & 8.75 \\
\hline Eng Writing & 8.47 & 9.07 & 8.47 & 8.68 & 8.62 \\
\hline
\end{tabular}




$\begin{array}{llllll}\text { Eng Speaking } & 8.55 & 9.10 & 8.60 & 8.81 & 8.54 \\ \text { Span Reading } & 8.15 & 8.12 & 7.78 & 7.94 & 8.16 \\ \text { Span Writing } & 7.5 & 7.61 & 6.94 & 7.5 & 7.16 \\ \text { Span Speaking } & 8.97 & 8.84 & 8.84 & 9 & 9\end{array}$

Stimuli. Stimuli consisted of 80 pictures selected from the Snodgrass and Vanderwart (1980) picture norms and other sources and the English and Spanish words that named these pictures. The pictures and words were a subset of those used in prior research (Francis et al., 2008), and they have been shown to be reliably named and relatively unambiguous. The words were divided into high-frequency and low-frequency sets. Frequency for English was determined using CELEX2 norms (Baayen, Piepenbrock, \& Gulikers, 1995). Frequency for Spanish words was assessed using the Alameda \& Cuetos (2005) frequency database. Average word length for low-frequency words was 5.8 and 6.4 letters for English and Spanish words respectively. Average word length for high-frequency words was 4.5 and 5.1 letters for English and Spanish respectively.

The words were divided into 4 different lists with 20 items each. Each version of the experiment involved presenting 80 words at study. Half of these words were English words and half were Spanish words. Additionally, within each language, half of the words were highfrequency and half were low-frequency. A high frequency word was one that had a frequency of at least 80 words-per-million (wpm) in both languages, and a low frequency word was one that had a frequency of less than $10 \mathrm{wpm}$ in both languages. At study, participants saw 40 highfrequency words in a mixed language list. Subsequently, participants saw 40 low-frequency words in a mixed language list. The order of presentation of high-and low-frequency lists was counterbalanced. 
At test, participants saw 80 pictures presented in a random sequence. Each picture represented one of the words studied in the encoding phase. Participants had to determine whether the word that named the picture was originally presented in English or Spanish.

\subsubsection{Design}

The independent variables formed a 2 (frequency) X 2 (language of instruction) mixed design. The levels of frequency were whether each item was a high- or low-frequency word, and the levels of language of instruction were whether the participant received the experimental protocol in English or Spanish. Frequency was manipulated within subjects, and language of instruction was manipulated between subjects. The dependent variables were language source discrimination (d') scores and lambda values (lambda is an index of bias in discrimination decisions).

\subsubsection{Procedure}

Participants were tested individually in sessions lasting approximately 50 minutes. Participants were first asked to complete the self-report language background questionnaire. Upon completion of the questionnaire, participants were administered tests 1 and 2 of the Woodcock-Muñoz battery. Participants were then given instructions on the computerized portion of the experiment. Participants were randomly assigned to receive exclusively English or exclusively Spanish instructions.

The computer portion of the experiment involved participants studying a mixed-language word list. Participants were told to commit the words to memory (with no mention of remembering the language source of the information). Participants saw 80 words appear on the screen one at a time. Words were presented for $2000 \mathrm{~ms}$ with a blank screen following every word for $1000 \mathrm{~ms}$.

At test, participants were told that they would see a set of pictures and that every picture corresponded to a word that they had studied previously. Participants were told that their task was to decide whether the item was originally presented in English or in Spanish. They recorded 
their responses on a button box, with buttons that had labels for English and Spanish. At the end of the test portion of the computerized experiment, participants were fully debriefed.

\subsubsection{Apparatus}

The computerized experiment was presented on an iMac desktop computer with a 17 monitor using PsyScope X B53 experiment software (Cohen, MacWhinney, Flatt, \& Provost, 1993). Responses were entered using a ioLab Systems button box.

\subsection{Results}

Discrimination Scores. Discrimination scores for the forced choice model were calculated for each participant (following Wickens, 2002). A discrimination score under the forced-choice model is the results of adding the z-score of the probability of response A to the $\mathrm{z}$ score of the probability of response B. This analysis yielded two sets of scores, one for highfrequency words and one for low-frequency words. The discrimination scores were submitted to a 2 (frequency) x 2 (language of instruction) mixed ANOVA. An advantage in discrimination was observed for low-frequency words $(M=1.51)$ relative to high-frequency words $(M=.97), F$ $(1,38)=20.17, M S E=.295, p<.001$. There was no main effect of language of instruction or interaction between frequency and language of instruction (all $p s>.05$ ). General accuracy on the language decision is presented in Table 2.

Lambda Scores. Lambda scores are an index of bias to respond. Under the forced-choice model, lambda scores indicate whether there is a tendency to respond with one choice rather than the other. In these studies, lambda scores indicated whether there was a preference to select one language more than the other. Lambda scores are calculated by obtaining half of d'. Each participant contributed two sets of lambda scores to the data, one for high-frequency and one for low-frequency words. The results were then submitted to a mixed ANOVA with language of instruction as a between subjects variable. There were no effects of frequency or language of instruction, and no interaction for language selection bias in Experiment 1, all ps $>.05$. 


\subsection{Discussion}

The results of Experiment 1 suggest that that the study of low-frequency words leads to a more robust source memory, one that makes retrieving language source information more accurate than for high-frequency words. The source-monitoring framework states that the source characteristics of memories that are more episodically distinct are more easily retrieved (Johnson et al., 1993), and this is indeed the case for low-frequency words. This pattern of results is also observed when considering contextual availability (Marsh, Cook, \& Hicks, 2006), presumably the low-frequency words here had lower contextual availability than the high-frequency words. Additionally, this discrimination effect is compatible with the source-of-activation-confusion theory (Diana \& Reder, 2006); which states that low-frequency words are recognized (and discriminated) more accurately because they are associated with fewer episodic encounters.

One of the novel contributions of this experiment to the source memory literature is the bridging of internal and external source memories. According to the source-monitoring framework, there is a separation between external and internal source memories (Johnson et al., 1993). Recall that external source memories are those that are experienced through the senses, and internal source memories are imagined events. Language and language source are experienced both internally and externally. Language exists internally, in the brain, in the lexicon; but it also exists externally, as we read words in different settings. For any given word in the study set, a participant had a linguistic representation that existed internally, prior to the external study episode. Semantic, contextual, cognitive, and semantic cues exist both internally and externally for words. Experiment 1 shows that memories that have both internal and external source representations can be accurately discriminated, and further that the cognitive operations required to make these discriminations are more accurate for low-frequency words.

The models of bilingual processing make a number of assumptions regarding bilingual access to words. One of the assumptions of the Costa model (Costa et al., 1999) is that lexeme and lemma level information is contained at the lexical level. Assuming only lexical access took place during the encoding phase of Experiment 1, the pattern of results suggest that this 
assumption is at least in part supported. The frequency issue is one not addressed by either the Costa model or the IC, but is incorporated into the BIMOLA where high-frequency words are perceived faster than low-frequency words. However, the BIMOLA is a model about speech processing, and makes no claims about long-term retention. However, if we assume that highfrequency words are less episodically distinct because they are easier to process, the results from Experiment 1 provide evidence that words that are more episodically distinct (e.g., lowfrequency words) leave a more robust source memory trace, one that makes the retrieval of source cues more accurate. Likewise, given that participants were reading words in isolation for Experiment 1, one could reasonably assume that some language tagging takes place during word recognition. Whether this language tagging is necessary for a word to be recognized is an issue not addressed here. The IC model makes the specific assumption that language membership information is stored at the lemma level. Assuming that lemma level access took place during the study phase in Experiment 1, and that the SAS allocated more resources to processing lowfrequency words, the pattern of results observed provides evidence of language tagging, at least in long-term memory.

Experiment 1 tested naive participants on their ability to retrieve the language source of words based on their pictures. At study, participants had to, at the very least, recognize words and commit them to memory. (They were not aware of the nature of the test they would be given.) At test, participants had to retrieve words based on their concepts (determine the word in each language that named the picture), and then subsequently decide what language the word was presented in at study. The results from this experiment inform the memory and bilingual literatures alike. First, a layer of specification is added to the source-monitoring framework; namely, in order to retrieve source information it is not necessary for the information at study to match the information given at test. Second, distinctive features (here, word frequency) of the information encoded make source retrieval more accurate. Third, and most importantly, language source is demonstrated to be an important contextual cue, one that deserves its own cue category in the source-monitoring framework. In terms of the bilingual processing models, Experiment 1 
provides evidence of language tagging when words are studied in isolation, and the maintenance of these tags in long-term memory. The results do not oppose any of the models of bilingual processing but they add a layer of knowledge to the after-effects of on-line processing. Initial contact with words leaves an episodic trace in long-term memory, and this trace is tagged for language.

\section{Chapter 3: Experiment 2}

Once we had tested the effects of word-frequency on memory for single words, the next natural step was to test language source memory for words embedded in a larger context. Experiment 2 tests language source discrimination for words embedded in sentence contexts. Participants memorized a mixed list of English-language and Spanish-language sentences. Each sentence contained a critical word that was tested later on language source recognition as in Experiment 1. All target words were the critical topic of the sentence and were positioned in subject or direct object position. Subsequently, at test, participants were shown a picture and they had to indicate whether the word that named the picture originally appeared in an English or Spanish sentence during the study phase. Half of the words were high frequency and half were low frequency, with equal numbers of high- and low-frequency words for English and Spanish. Additionally, language of instruction was manipulated. Participants were randomly assigned to receive either exclusively English or exclusively Spanish instructions for the entire experimental protocol.

\subsection{Method}

\subsubsection{Participants}

Forty English-Spanish bilinguals (27 women, 13 men) were recruited from the psychology participant pool at the University of Texas at El Paso (see Table 1). Students were given course credit for their participation. Objective proficiency measures obtained from the

WMLS-R determined that 23 participants were English dominant and 17 were Spanish- 
dominant, and all but two participants reported learning Spanish prior to English. (Summary information on participants is presented in Table 1.). Students were given course credit for their participation.

\subsubsection{Materials}

The materials were the same as in Experiment 1 except that the critical words were embedded in short sentences at study. The sentences were 4-8 words in length and the critical word always appeared in subject or direct object position. The target words were not marked as different from the other words in the sentence.

\subsubsection{Design}

The independent variables formed a 2 (frequency) X 2 (language of instruction) within subjects design. The levels of frequency were whether the target word is a high- or lowfrequency word, and the levels of language were whether the participant received instructions in English or Spanish. The dependent variables were language source recognition discrimination scores and lambda values.

\subsubsection{Procedure}

Participants completed the same questionnaire and language assessments as in Experiment 1. The computer portion of the experiment involved participants studying English and Spanish language sentences in a mixed sequence. Participants were told to commit the sentences to memory (with no mention of remembering the language source of the information). Participants saw 80 sentences appear on the screen one at a time, and were asked to press a button once they were done reading each sentence. A blank screen appeared for $1000 \mathrm{~ms}$ between sentence trials.

At test, participants were told that they would see a set of pictures and that every picture named a word that had been part of a sentence at study. Participants were told that their task was to decide whether the word that named the picture was originally in an English or in a Spanish 
sentence. They recorded their responses on a button-box as in Experiment 1. Participants were subsequently debriefed.

\subsubsection{Apparatus}

The experiment was presented using the same apparatus as in Experiment 1.

\subsection{Results}

Discrimination Scores. A frequency effect was observed such that the language source of low-frequency words $(M=1.42)$ was more accurately discriminated than the language source of high-frequency words $(M=.87), F(1,38)=20.46, M S E=.295, p<.001$. There was no main effect of language of instruction or interaction between frequency and language of instruction $($ all $p s>.05)$. Performance in Experiment 2 was expected to be significantly worse than in Experiment 1. A planned 2 (frequency) X 2 (language of instruction) X 2 (experiment) mixed ANOVA was performed and there was no significant difference in performance levels between Experiments 1 and $2(p>.05)$. See Table 2 for general accuracy.

Lambda Scores. There were no effects of frequency or language of instruction and no interaction for language selection bias in Experiment 2, all $p s>.05$.

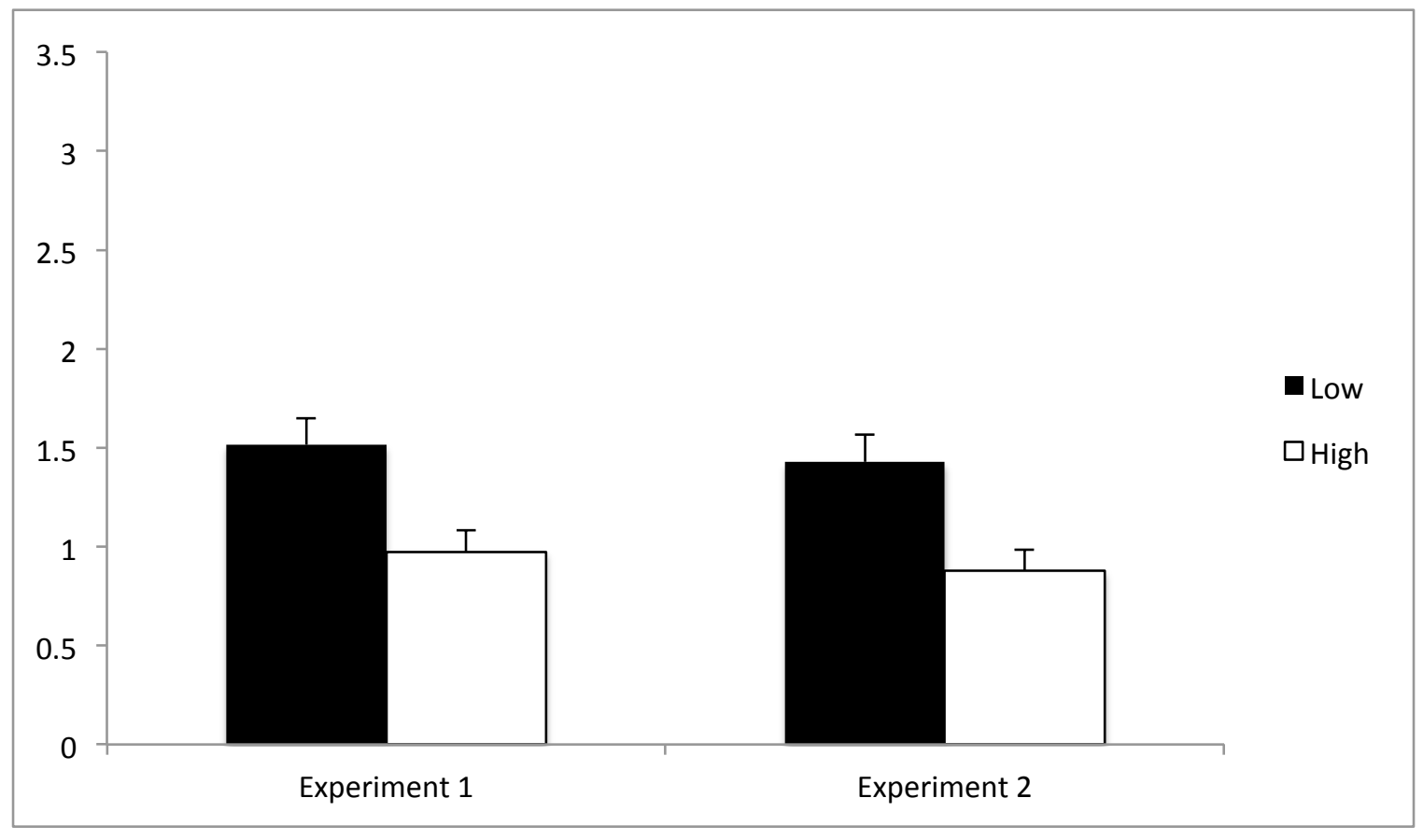


Figure 3.1: Discrimination Scores for Low- and High-Frequency Words Presented in Isolation or Sentence Context

\subsection{Discussion}

Experiments 1 and 2 showed the same pattern of results: greater accuracy in discriminating language source for low-frequency words. These results support the same theoretical conclusions as those in Experiment 1; low-frequency words are more distinct, and that leads to a more robust source memory for language, one that makes the language of the word more easily retrieved.

However, discrimination scores for words in Experiment 2 were predicted to be significantly lower than for Experiment 1, this prediction was not supported by the data. The prediction was based upon reading effects in the literature that suggest that words in a sentence are processed as part of a larger structure, and the characteristics of any one word are not as salient because the word is part of a larger representation (e.g., Potter \& Lombardi, 1990; Sachs, 1967). The source-monitoring framework holds that the type and number of characteristics a memory is encoded with determine whether it leaves a more or less robust source trace. According to this logic then, we should observe a benefit from sentence context. Words in Experiment 2 had a rich context that could potentially have made the language source more salient, but this was not the case either. The results suggest that a sentence context neither aids nor hinders participants' ability to discriminate language source information. This effect seems to be at odds with memory findings that show an item-recognition advantage for words studied in isolation (e.g., Strobach et al., 2013); recall that discrimination is partly a recognition-based memory process. These results support the idea that although source memory is recognition based, it is independent from recognition memory. Similarly the lack of significant differences in performance between Experiments 1 and 2 is not directly compatible with any of the models of bilingual processing; all three models argue that providing more linguistic information (here by virtue of a larger context) makes language selection and word processing less taxing, which suggests that discrimination would be better for words in context. Here, the availability of a 
larger context had no effect on participants' ability to discriminate the language of study. One possibility is that the language source trace is set from the onset of the sentence, such that the information is stored in long-term memory as it would be for an isolated word. Another possibility is that language tagging and language source encoding occurs relatively early in processing, perhaps even at the word recognition stages, such that the influence of a sentence context is minimal at best. The third possibility is that the same level of lemma-engagement is present when reading words in isolation and as part of a larger sentence context, thus leading to no differences in source retrieval. 


\section{Chapter 4: Experiment 3}

Given that both Experiments 1 and 2 relied on perceptual study phases, we wanted to test whether the more effortful process of word production would lead to more accurate source retrieval. Participants produced a mixed sequence of English and Spanish words in response to picture cues and tried to commit them to memory. At test, participants were shown a picture and had to indicate whether they originally named the picture in English or Spanish. Half of the words were high frequency, and half were low frequency, with equal numbers of high- and lowfrequency words for English and Spanish. Additionally, language of instruction was manipulated. Participants were randomly assigned to receive either exclusively English or exclusively Spanish instructions for the entire experimental protocol.

\subsection{Method}

\subsubsection{Participants}

Forty English-Spanish bilinguals (26 women, 14 men) were recruited from the psychology participant pool at the University of Texas at El Paso. Students were given course credit for their participation. Objective proficiency measured obtained from the WMLS-R determined that 28 participants were English dominant and 12 were Spanish dominant, and all but one participant reported learning Spanish prior to English. (Summary information on participants is presented in Table 1.). Students were given course credit for their participation.

\subsubsection{Materials}

The materials were the same as in Experiment 1.

\subsubsection{Design}

The independent variables formed a 2 (frequency) X 2 (language of instruction) mixed design. The levels of frequency were whether the target word was a high- or low-frequency word, and the levels of language were whether the participant received instructions in English or 
Spanish. The dependent variables were language source recognition discrimination scores and lambda values.

\subsubsection{Procedure}

Participants completed the same questionnaire and language assessments as in Experiments 1 and 2. The computer portion of the experiment involved having participants produce mixed language word sequences in response to pictures. Participants were cued to the appropriate response language for each picture by a screen that displayed the word say for English responses, and diga for Spanish responses. Participants produced 80 words. A blank screen appeared on the screen for $1000 \mathrm{~ms}$ between production trials.

At test, participants were told that they would see a set of pictures and that every picture was one that they had named at study. Participants were told that their task was to decide whether they originally named the picture in English or in Spanish. Responses were recorded on a button box, with the buttons clearly labeled for language. Participants were debriefed.

\subsubsection{Apparatus}

The experiment was presented using the same apparatus as in Experiments 1 and 2.

\subsection{Results}

Encoding Phase Accuracy. Participants were 94\% accurate in naming the pictures at study.

Discrimination Scores. A frequency effect was observed such that the language source of low-frequency words $(M=3.10)$ was more accurately discriminated than the language source of high-frequency words $(M=2.38), F(1,38)=24.09, M S E=.438, p<.001$. No main effect of language of instruction or interaction between frequency and language of instruction was observed (all ps $>.05$ ). Performance in Experiment 3 was expected to be significantly better than in Experiment 1. A planned 2 (frequency) X 2 (language of instruction) X 2 (experiment) mixed ANOVA was performed and indeed discrimination was more accurate if the word was produced 
$(M=2.74)$ rather than $\operatorname{read}(M=1.25)$ at study, $F(1,76)=83.73, M S E=1.063, \mathrm{p}<.001$. See Table 2 for general accuracy on the discrimination task.

Lambda Scores. There were no effects of frequency or language of instruction and no interaction for language selection bias in Experiment 3, all $p s>.05$.

\subsection{Discussion}

Experiments 1 and 3 showed the same pattern of results: higher language source discrimination scores for low-frequency words. Word saliency is the underlying cause of the advantage in discrimination of language source for low-frequency words. However, consistent with predictions, discrimination scores for Experiment 3 were significantly higher than for Experiment 1. Experiment 3 placed different processing demands on participants. In Experiment 3, participants produced each word at study. Essentially, participants viewed a picture, and based upon language cue information, produced a word in a particular language. The advantage for words produced in Experiment 3 is indicative of a generation effect (Gardiner, Gregg, \& Hampton, 1988) where production in response to a cue leads to more accurate item recognition. This effect is also observed in source discrimination (Nieznański, 2012) and is consistent with the assumptions of the source-monitoring framework; specifically, that participants had more contextual information and greater cognitive demand at study, which led to more robust encoding of language source information.

The models of bilingual memory do not directly tackle the issue of picture naming, or word access in general in response to cues. However, as mentioned, the IC model specifies lemma-level access to language membership information. Here we assume that lemma-level access occurred for every picture naming trial, because picture naming involves conceptual access. The finding from Experiment 3 also suggests that during naming, lemma-level information is targeted and selected, and this in turn leads to more accurate discrimination, directly supporting the IC's storage of the language tag at the lemma level. Similarly, the evidence here suggests that although lexeme and lemma-level information can be stored at the 
lexical level (as in Costa et al., 1999; 2005), the selection of lemma-level information for tagging during picture naming shows that these levels can be differentially activated, even within the lexical level. The results from Experiment 3 suggest that as more complex linguistic operations take place (producing a word from the lexicon is more effortful than reading a word that has been provided) language source information becomes a much more salient part of the study episode.

One interesting test of the assumptions of the source-monitoring framework provided by Experiment 3 is the test of the effects of cognitive operations at encoding and retrieval. Experiment 3 is the only experiment in this series that placed similar cognitive demands on participants at encoding and retrieval, and indeed this led to an advantage in discrimination over Experiment 1. In Experiments 1 and 2, participants had to recall the study episode in its entirety in order to remember the language source of the words, in Experiment 3 some of the cues were present at retrieval and that may have been a factor in making language source discrimination more accurate. 


\section{Chapter 5: Experiment 4}

One aspect of the perceptual processing system not tested thus far is the issue of whether modality impacts memories for language source. Under the source-monitoring framework one should not expect differences between words that are read and words that are heard, in fact studies looking specifically at source discrimination for these two modalities have found no differences (Marsh et al., 2006). The BIMOLA (Grosjean, 1988) specifies that phoneme perception takes place without language cues, and in a language-specific manner. Experiment 4 sheds light on how auditory information affects language source retrieval. Participants heard a mixed sequence of English and Spanish words and committed the words to memory. At test, participants were shown a picture and had to indicate whether the word that named the picture was originally heard in English or Spanish. Half of the words were high frequency and half were low frequency, with equal numbers of high- and low-frequency words for English and Spanish. Additionally, language of instruction was manipulated. Participants were randomly assigned to receive either exclusively English or exclusively Spanish instructions for the entire experimental protocol.

\subsection{Method}

\subsubsection{Participants}

Forty English-Spanish bilinguals (22 female) were recruited from the psychology pool at the University of Texas at El Paso. Objective proficiency measures obtained from the WMLS-R determined that 26 participants were English dominant and 14 were Spanish dominant, and all but three participants reported learning Spanish prior to English. (Summary information on participants is presented in Table 1). Students were given course credit for their participation.

\subsubsection{Materials}

The materials were the same as in Experiment 1 . The words were recorded by a female native speaker of English and Spanish. 


\subsubsection{Design}

The independent variables formed a 2 (frequency) X 2 (language of instruction) mixed design. The levels of frequency were whether the target word was a high- or low-frequency word, and the levels of language were whether the participants received instructions in English or Spanish. The dependent variables were language source recognition discrimination scores and lambda values.

\subsubsection{Procedure}

Participants completed the same questionnaire and language assessments as in Experiment 1. The computer portion of the experiment involved participants hearing words in a mixed language order. A blank screen appeared before every trial, the screen was presented for $1000 \mathrm{~ms}$. A screen with a fixation point then appeared for $2000 \mathrm{~ms}$. Participants were presented with the target word audio file during this time.

At test, participants were told that they would see a set of pictures and that their task was to decide whether the word that named the picture was originally heard in English or Spanish. Participants were debriefed.

\subsubsection{Apparatus}

The experiment was presented using the same apparatus as in Experiments 1, 2, and 3.

\section{$5.2 \quad$ Results}

Discrimination Scores. A frequency effect was observed such that the language source of low-frequency $(M=1.30)$ words were more accurately discriminated than the languge source of high-frequency words $(M=.91), F(1,38)=9.68, M S E=.333, \mathrm{p}<.05$. There was no main effect of language of instruction $p>.05$. However, a marginal interaction between frequency and language of instruction was observed such that the low-frequency advantage was greater when instructions were given in English, $F(1,38)=3.97, p=.053$. Performance in Experiment 4 was expected to be similar to Experiment 1 but significantly worse than Experiment 3. Planned comparisons between Experiment 1 and 4 show no difference in language source discrimination 
between Experiments 1 and 4, all ps $>.05$. The planned comparison between Experiment 3 and 4 similarly supports the predictions in that performance in Experiment $3(M=2.74)$ was significantly better than performance in Experiment $4(M=1.10), F(1,76)=110.16, M S E=$ $.975, p<.001$. See Table 2 for general accuracy on the discrimination task.

Lambda Scores. There were no effects of frequency or language of instruction and no interaction for language selection bias in Experiment 4, all $p s>.05$.

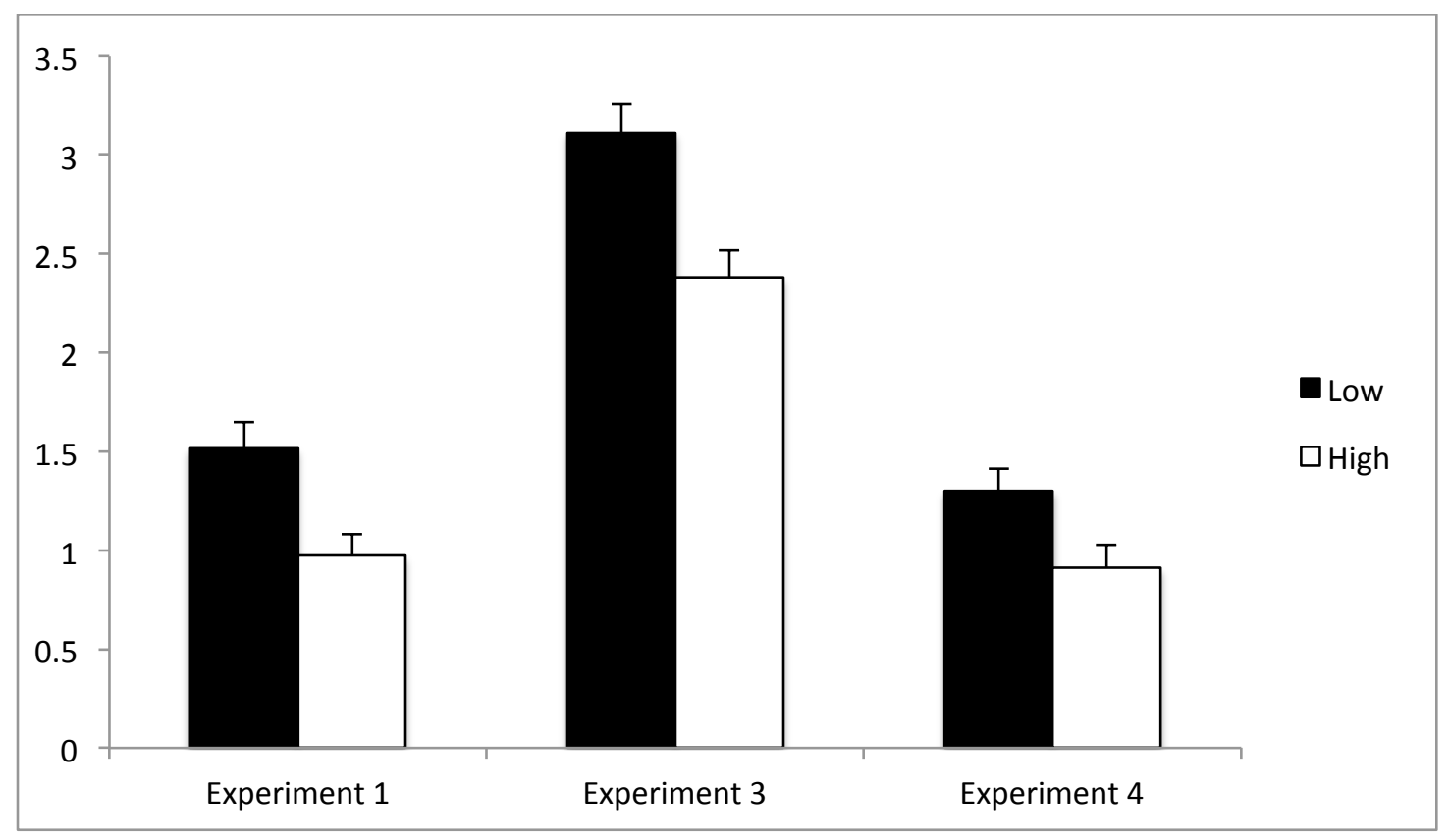

Figure 5.1: Discrimination Scores for Low- and High-Frequency Words as a Function of Perceptual and Conceptual Task Demands

\subsection{Discussion}

Experiment 4 directly tested whether phonemic perception of words led to better discrimination of language source information. This experiment provided more evidence for some of the assumptions of the source-monitoring framework; namely, more contextual information leads to more accurate source discrimination. The study phases in Experiments 1 and 4 were both perceptual in nature; in Experiment 1, participants were asked to read words, and in Experiment 4, they were asked to listen to words. If we assume that the encoding tasks in both 
experiments were perceptual in nature, the lack of a significant difference in performance between the experiments lies in the fact that they had the same amount of contextual information from which to create a source memory. In contrast, Experiment 3 is conceptual in nature, because participants have to find the appropriate label for the picture and then produce it. Therefore, more contextual information is available to construct a more robust language source memory. Similarly, Experiments 1 and 4 required the same level of lemma-level access, whereas Experiment 3 required strong lemma-level engagement. The pattern of results observed here thus lends more support for the IC's assumption that language tagging occurs at the lemma-level.

The only model that makes specific assumptions about words presented auditorially is the BIMOLA. This model assumes that speech perception operates in a language-specific manner at the phoneme level. Experiment 4 directly tested and found no support for this assumption. If phoneme perception was indeed language-specific, performance in Experiment 4 should have been significantly better than performance in Experiment 1, but this was not the case. The fact that words were presented auditorially did not benefit language source encoding over reading words silently. In the experiments discussed so far, there is a clear language source discrimination advantage for low-frequency words and for words that are produced rather than comprehended. 


\section{Chapter 6: Experiment 5}

Experiment 5 tests the effect of languages in contact on language source retrieval to find out whether processing a word in both languages causes source confusion. Participants translated a mixed list of English and Spanish words and attempted to commit the words to memory. Each word was translated into the opposite language. That is, if a word was presented in English, then it was translated to Spanish and vice versa. At test, participants were shown a picture and they had to indicate whether the word that named the picture originally appeared in English or Spanish, prior to translation. Half of the words were high frequency and half were low frequency, with equal numbers of high- and low-frequency words for English and Spanish. Additionally, language of instruction was manipulated. Participants were randomly assigned to receive either exclusively English or exclusively Spanish instructions for the entire experiment protocol.

\subsection{Method}

\subsubsection{Participants}

Forty English-Spanish bilinguals (29 women, 11 men) were recruited from the psychology participant pool at the University of Texas at El Paso. Objective proficiency measures obtained from the WMLS-R determined that 22 participants were English dominant and 18 were Spanish dominant, and all but two participants reported learning Spanish prior to English. (Summary information on participants is presented in Table 1). Students were given course credit for their participation.

\subsubsection{Materials}

The materials were the same as in Experiment 1.

\subsubsection{Design}

The independent variables formed a 2 (frequency) X 2 (language of instruction) within subjects design. The levels of frequency were whether the target word was a high- or low- 
frequency word, and the levels of language were whether the participants received instructions in English or Spanish. The dependent variables were language source recognition discrimination scores and lambda values.

\subsubsection{Procedure}

Participants completed the same questionnaire and language assessments as in Experiment 1.

The computer portion of the experiment involved participants translating mixed language word lists. Participants were told to translate the words into English or Spanish depending on the language of presentation, and no mention was made of the test task. Participants translated 80 words, and response times were recorded using a microphone. A blank screen appeared on the screen for $1000 \mathrm{~ms}$ between translation trials.

At test, participants were told that they would see a set of pictures and that every picture named a word that they had to translate at study. Participants were told that their task was to decide whether the word that named the picture was originally in English or in Spanish. Responses were recorded on a button box, with the buttons clearly labeled for each language. Participants were debriefed.

\subsubsection{Apparatus}

The experiment was presented using the same apparatus as in Experiments 1, 2, 3, and 4.

\subsection{Results}

Encoding Phase Accuracy. Participants were $93 \%$ accurate in translating the words at study.

Discrimination Scores. A frequency effect was observed such that the language source of low-frequency $(M=1.90)$ words was more accurately discriminated than the language source of high-frequency words $(M=1.01), F(1,38)=66.19, M S E=.242, p<.001$. No main effect of language of instruction or interaction between frequency and language of instruction was observed (all ps $>.05$ ). Performance in Experiment 5 was expected to be significantly better than 
in Experiment 1 and similar to Experiment 3 if production was the source of the advantage in language source discrimination. A planned 2 (frequency) X 2 (language) X 2 (experiment) mixed ANOVA was performed comparing the performance in Experiment 5 to that of Experiment 1 and there was no significant difference in performance, $p>.05$. However, performance in Experiment $5(M=1.46)$ was significantly worse than performance in Experiment $3(M=2.74)$, $F(1,76)=44.10, M S E=1.492 p<.001$. In order to explore the comprehension/production hypothesis further, a post-hoc pairwise comparison between Experiment 4 (auditory perception) and Experiment 5 was made, discrimination in Experiment 5 was significantly more accurate than discrimination in Experiment $4, F(1,76)=4.14, M S E=1.228, p<.05$. See Table 2 for general accuracy on the discrimination task.

Lambda Scores. There were no effects of frequency or language of instruction and no interaction for language selection bias in Experiment 5, all $p s>.05$.

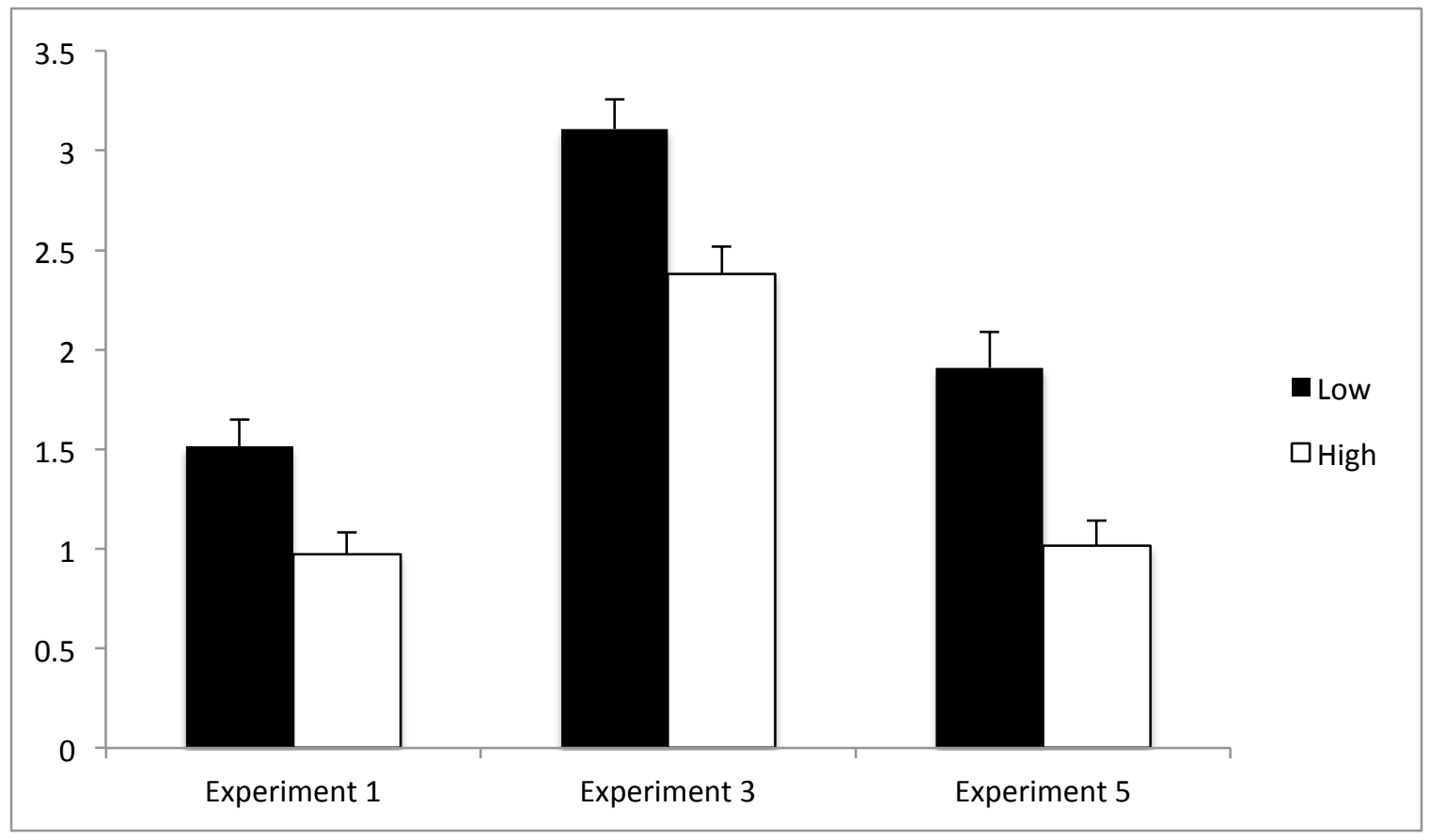

Figure 6.1: Discrimination Scores for Low- and High-Frequency Words as a Function of Comprehension and Production. 
Table 2: Language Source Recognition Accuracy

\begin{tabular}{lllll} 
Experiment & English $\mathbf{H F}$ & English $\mathbf{L F}$ & Spanish $\mathbf{H F}$ & Spanish $\mathbf{L F}$ \\
\hline $\mathbf{1}$ & $68.1 \%$ & $74.3 \%$ & $65.1 \%$ & $75.4 \%$ \\
$\mathbf{2}$ & $66.8 \%$ & $75.8 \%$ & $60 \%$ & $70.5 \%$ \\
$\mathbf{3}$ & $85.2 \%$ & $89.6 \%$ & $85.9 \%$ & $92.3 \%$ \\
$\mathbf{4}$ & $64.8 \%$ & $73.5 \%$ & $65.3 \%$ & $69.6 \%$ \\
$\mathbf{5}$ & $73.2 \%$ & $81.8 \%$ & $62.5 \%$ & $76 \%$
\end{tabular}

\subsection{Discussion}

One of the goals of Experiment 5 was to determine whether participants can remember the language source of words presented when both of their languages are accessed. We expected performance in this experiment to be significantly worse than in all other experiments because we assumed that the fact that translating an item requires comprehending a word in one language and producing it in the other would make it difficult for participants to recall the direction of the translation when tested on a neutral conceptual cue (the picture). However, performance in Experiment 5 was not significantly different that performance in Experiment 1 (a perceptually based experiment), but significantly better than performance in Experiment 4. One interpretation for the advantage of translation over auditory encoding is that participants encode portions of the translation process separately. For instance, when translating perro into dog, participants remember that perro was presented, and that they had to search for dog. Thus, if they are subsequently asked about source details of either of those decisions the discrimination of source is not compromised. In line with predictions, performance in Experiment 5 was significantly worse than performance in Experiment 3.

The second aim of Experiment 5 was to test some of the assumptions of the sourcemonitoring framework; namely, the idea that there is an internal/external reality monitoring 
process that occurs as we sort out source memories. Although the specific examples refer to real or imagined memories (Johnson et al., 1993), the same logic could be applied to Experiment 5. One of the requirements of Experiment 5 was that participants, unknowingly, encode information regarding the direction of translation at study. For instance, participants had to know that they saw the word appear in Spanish on the screen, and that they translated to English, in order to be able to discriminate the language source of the word that appeared on the screen. Essentially participants were keeping track of two sets of contextual details. Participants in these experiments were never made aware of the nature of the test task, precisely because we wanted to investigate whether language source monitoring happened spontaneously. Experiment 5 is a direct test of language source monitoring, participants kept two separate logs of language source processes, as mentioned previously, and were subsequently able to discriminate between them. Not only does Experiment 5 provide support for the source-monitoring framework's internal/external reality monitoring, but also for the SAS in the IC. The IC posits that the SAS allocates processing resources according to task demands. Indeed, translation is specifically discussed in Green (1998) as a special instantiation of inhibitory control were both languages are active in order to complete the translation task. Recall too that executive control is thought to be a major contributor to source discrimination (Parkin \& Leng, 1993; Wheeler et al., 1997). The results in Experiment 5 support the idea that as encoding is taking place, language tagging occurs, and these tags are encoded into long-term memory and available for episodic retrieval. 


\section{Chapter 7: General Discussion}

The main question explored in this dissertation was the issue of how language source information influences long-term memory and episodic retrieval. The source-monitoring framework is underspecified with respect to how different types of source memories come to be

encoded, how they are retrieved, and to what extent contextual cues play a role in source encoding. Likewise, the three main models of bilingual processing have different assumptions regarding the representation of language source information, and none allude to how language source information is stored in long-term memory.

The experiments tested several aspects of the source-monitoring framework. First, the experiments tested source discrimination for words presented in two languages. Using words provided a unique test of the types of source memories proposed by the source-monitoring framework (internal and external). Internal source representations are imagined, or derived from thought, not directly experienced; and external source representations are directly experienced through the senses (Johnson et al., 1993). Words share both characteristics, they exist internally in our lexicon, and they are experienced externally as we interact with the world and the people around us. The experiments here provided support for the idea of a process dedicated to monitoring internal/external sources by testing episodic retrieval of language source information for words that exist both internally and externally. Participants had to remember that they saw a particular word that was known to them, and they also had to remember that they saw this word in a particular language, in the context of an experiment.

Secondly, the experiments tested whether episodic distinctiveness would benefit source retrieval. Consistently, across all five experiments, the language source of low-frequency words was more easily discriminated than the language source of high-frequency words. This finding suggests that memories that are salient in some way are more likely to lead to robust source encoding. Although there is much left to explore, and many assumptions of the sourcemonitoring framework remain to be tested, these experiments provide some support for the 
framework. The results of the experiments here also show that some specification of source memory types is warranted. Johnson and colleagues (1993) suggest that there is a clear distinction between internally vs. externally derived memories, and for most of our memories this may very well be the case. However, the study of words clearly provides an instance in which a memory can have both internally derived, and externally experienced cues that lead to source monitoring and encoding, and the evidence here warrants that addition to the model.

Third, the experiments tested the extent to which contextual cues play a role in source encoding. By varying the task that participants performed at study, we were able to directly test whether varying the degree of contextual information affected language source encoding. Specifically, the experiments demonstrate that production of words at study leads to a greater advantage in language source discrimination. In the larger scope of source monitoring, this finding suggests that processes that are more cognitively effortful lead to stronger source encoding.

One of the aims of this dissertation was to begin to bridge the gap between the source monitoring literature and the models of bilingual processing to pave the way for models that explain on-line processing as well as the long-term effects of processing words in more than one language. Currently, the main models of bilingual processing do not address the long-term memory consequences of processing words in a bilingual environment. Under the IC, language tagging takes place at the lemma-level of a word, and the significant advantage of picture naming observed here supports that assumption. Costa et al. $(1999 ; 2005)$ argue that lexeme and lemmalevel information is stored at the lexical level of a word, and this assumption is supported by the results of Experiments 1,2, and 4 as well as the lack of a significant difference in performance between Experiments 1 and 2. However, the fact that performance in Experiment 3, the picture naming experiment, suggests that some aspects of lemma-level information can be uniquely activated and lead to stronger language tagging.

In addition to the issue of whether the language tag is contained at the lemma level, we tested whether the phonological system was particularly sensitive to language source 
information. The BIMOLA holds that language tags are essential to the storage of phonemes, and that auditory speech perception is particularly attuned to these cues. The issue of languagespecific phoneme storage isn't directly tested in this dissertation. However, the results of Experiment 4, where participants heard words, do not support the idea that auditory speech perception leads to any more language tuning than visual perception, from a long-term memory perspective. One of the other aspects of the BIMOLA tested here is the issue of the bilingual mode. We tested the idea of the bilingual mode by manipulating the language of instruction. Language of instruction had no effect on language source discrimination. Finally, we tested some of the assumptions of the IC by manipulating task demands, and language monitoring (Experiment 5). The evidence here suggests that bilinguals effectively monitor, manage, and tag for languages while processing. Experiment 5 required that participants keep track of several linguistic events occurring in a matter of seconds, and these processes were strong enough to leave a long-term memory trace that was subsequently retrieved.

The experiments here begin to pave the way to bridging the bilingual processing and source memory literatures together. The results suggest that the processes that take place as bilinguals process words are compatible and similar to the processes that take place as they store linguistic events in long-term memory. From a second-language learning perspective, we can begin to understand how it is that fluent bilinguals keep track of information from two sources, often simultaneously, and how this information is strong enough to leave an episodic trace. Here the results suggest that language source information is more easily discriminated for words that are salient, and for words that are produced. Those two findings lend support the idea of exposing learners of a second language to activities that are conversational in nature. This would be especially recommended for early learners for whom most of the words in the second language are of lower frequency.

Moving forward, research should investigate the specific underlying mechanism for the production advantage in discrimination. Additionally, the specific pattern of results should be tested in less fluent bilingual speakers. Likewise, it might be fruitful to investigate whether 
children, or older adults, whose ability to discriminate source information has not developed or has declined, are able to discriminate language source information at the same rate as collegeaged university populations. Strengthening the connections between the source literature and the bilingual processing literature has consequences for how we understand not only the bilingual mind but also the architecture of the memory system in general. 


\section{References}

Alameda, J. R., \& Cuetos, F. (1995). Diccionario de frecuencia de las unidades lingüísticas del castellano. Oviedo: Universidad de Oviedo.

Altarriba, J. (1992). The representation of translation equivalents in bilingual memory. In R. J. Harris (Ed.), Cognitive processing in bilinguals (pp.157-174). Amsterdam: Elsevier Science.

Altarriba, J., Kroll, J. F., Sholl, A., \& Rayner, K. (1996). The influence of lexical and conceptual constraints on reading mixed-language sentences: Evidence from eye fixations and naming times. Memory and Cognition, 24, 477-492.

Altenberg, E. P., \& Smith Cairns, H. (1983). Phonotactic constraints on lexical processing in bilingual and monolingual subjects. Journal of Verbal Learning and Verbal Behavior, 22, 174-188.

Amastae, J. (in preparation). A course in phonology. The University of Texas at El Paso.

Baddeley, A. D., Papagno, C, \& Vallar, G. (1988). When long-term learning depends on shortterm storage. Journal of Memory and Language, 27, 586-595.

Balota, D. A., Cortese, M. J., Duchek, J. M., Adams, D., Roediger III, H. L., McDermott, K. B., \& Yerys, B. E. (1999). Veridical and false memories in healthy and older adults and in dementia of the Alzherimer's type. Cognitive Neuropsychology, 16, 361-384.

Baayen, R., Piepenbrock, R., \& Gulikers, L. (1995). CELEX2 LDC96L14. Web download. Philadelphia: Linguistic Data Consortium.

Becker, S., Moscovitch, M., Behrmann, M., \& Joordens, S. (1997). Long-term semantic priming: A computational account and empirical evidence. Journal of Experimental Psychology: Learning, Memory, and Cognition, 23, 1059-1082.

Boada, R., Sánchez-Casas, R., Gavilán, J. R., García-Albea, J. E., \& Tokowicz, N. (2013). Effect of multiple translations and cognate status on translation recognition performance of balanced bilinguals. Bilingualism: Language and Cognition, 16, 183-197.

Bürki-Cohen, J., Grosjean, F., \& Miller, J. L. (1989). Base-language effects on word identificationin bilingual speech: Evidence from categorical perception experiments. Language and Speech, 32. 355-371.

Byers-Heinlein, K., Burns, T. C., \& Werker, J. F. (2010). The roots of bilingualism in newborns. Psychological Science, 21, 343-348.

Chauncey, K., Grainger, J., \& Holcomb, P. J. (2008). Code-switching effects in bilingual word recognition: A masked priming study with event-related potentials. Brain and Language, 105, 161-174.

Chua, H. F., Chen, W., \& Park, D. C. (2006). Source memory, aging and culture. Gerontology, $52,306-313$.

Cohen, J., MacWhinney, B., Flatt, M., \& Provost, J. (1993). Psyscope: An interactive graphic system for designing and controlling experiments in the psychology laboratory using 
Macintosh computers. Behavior Research Methods, Instruments, \& Computers, 25, 257271.

Costa, A., \& Caramazza, A. (1999). Is lexical selection in bilingual speech production languagespecific? Further evidence from Spanish-English and English-Spanish bilinguals. Bilingualism: Language and Cognition, 2, 231-244.

Costa, A., Miozzo, M., \& Caramazza, A. (1999). Lexical selection in bilinguals: Do words in the bilingual's two lexicons compete for selection? Journal of Memory and Language, 41, 365-397.

Costa, A., Santesteban, M., Caño, A. (2005). On the facilitatory effects of cognate words in bilingual speech production. Brain and Language, 94, 94-103.

Crawley, S. L., Newcombe, N. S., \& Bingman, H. (2010). How focus at encoding affects children's source monitoring. Journal of Experimental Child Psychology, 105, 273-285.

Cristoffanini, P., Kirsner, K., \& Milech, D. (1986). Bilingual lexical representation: The status of Spanish-English cognates. Quarterly Journal of Experimental Psychology: Human Experimental Psychology, 38, 367-393.

de Groot, A. M. B., Borgwaldt, S., Bos, M., \& van den Eijnden, E. (2002). Lexical decision and word naming in bilinguals: Language effects and task effects. Journal of Memory and Language, 47, 91-124.

de Groot, A. M. B., Delmaar, P., \& Lupker, S. J. (2000). The processing of interlexical homographs in translation recognition and lexical decision: Support for non-selective access to bilingual memory.

de la Riva López, E., Francis, W. S., \& García, J. (2012). Repetition priming within and between languages in verb generation: Evidence for shared verb concepts. Memory, 20, 358-373.

Diana, R. A., \& Reder, L. M. (2006). The low-frequency encoding disadvantage: Word frequency affects processing demands. Journal of Experimental Psychology: Learning, Memory, and Cognition, 32, 805-815.

Dijkstra, T. (2009). Bilingual visual word recognition and lexical access. In J. F. Kroll \& A. B. De Groot (eds.), Handbook of Bilingualism: Psycholinguistic Approaches, pp. 179-201. New York: Oxford University Press.

Dijkstra, T., Grainger, J., \& van Heuven, W. J. B. (1999). Recognition of cognates and interlingual homographs: The neglected role of phonology. Journal of Memory and Language, 41, 496-518.

Dijkstra, T., Miwa, K., Brummelhuis, B., Sappelli, M., \& Baayen, H. (2010). Language similarity and task demands affect cognate recognition. Journal of Memory and Language, 62, 284-301.

Dijkstra, T., \& van Heuven, W. J. B. (2002). The architecture of the bilingual word-recognition system: From identification to decision. Bilingualism: Language and Cognition, 5 (3), 175-197. 
Dijkstra, T., van Jaarsveld, H., \& Brinke, T. (1999). Interlingual homograph recognition: Effects of task demands and language intermixing. Bilingualism: Language and Cognition, 1, 5166.

Durgunoglu, A. Y., \& Roediger, H. L. (1987). Test differences in accessing bilingual memory. Journal of Memory and Language, 26, 377-391.

Dussias, P. E., \& Cramer Scaltz, T. R. (2008). Spanish-English L2 speakers' use of subcategorization bias information in the resolution of temporary ambiguity during second language reading. Acta Psychologica, 128, 501-513.

Duyck, W., Vanderelst, D., Desmet, T., \& Hartsuiker, R. J. (2008). The frequency effect in second-language visual word recognition. Psychonomic Bulletin and Review, 15, 850855.

Elston-Gütler, K. E., Paulmann, S., \& Kotz, S. A. (2005). Who's in control? Proficiency and L1 influence on L2 processing. Journal of Cognitive Neuroscience, 17, 1593-1610.

Francis, W. S. (1999). Cognitive integration of language and memory in bilinguals: Semantic representation. Psychological Bulletin, 125, 193-222.

Francis, W. S., Augustini, B. K., \& Sáenz, S. P. (2003). Repetition priming in picture naming and translation depends on shared processes and their difficulty: Evidence from SpanishEnglish bilinguals. Journal of Experimental Psychology: Learning, Memory, and Cognition, 29, 1283-1297.

Francis, W. S., Corral, N. I., Jones, M. L., \& Sáenz, S. P. (2008). Decomposition of repetition priming components in picture naming. Journal of Experimental Psychology: General, 137, 566-590.

Francis, W. S., Fernández, N. P., \& Bjork, R. A. (2010). Conceptual and non-concetual repetition priming in category exemplar generation: Evidence from bilinguals. Memory, 18, 787789.

Francis, W. S. \& Gallard, S. L. K. (2005). Concept mediation in trilingual translation: Evidence from response times and repetition priming patterns. Psychonomic Bulletin \& Review, 12, 1082-1088.

Francis, W. S., \& Goldmann, L. L. (2011). Repetition priming within and between languages in semantic classification of concrete and abstract words. Memory, 19, 653-663.

Francis, W. S., \& Gutiérrez, M. (2012). Bilingual recognition memory: Stronger performance but weaker levels-of-processing effects in the less fluent language. Memory and Cognition, 40, 496-503.

Francis, W. S., \& Strobach, E. N. (2013). The bilingual L2 advantage in recognition memory. Psychonomic Bulletin and Review, 20, 1296-1303.

Francis, W. S., \& Strobach, E. N. (2013a). Prediction of objective bilingual language proficiency: Can self-report measures suffice? Abstract of the Psychonomic Society, 18, 34. 
Francis, W. S., Tokowicz, N., \& Kroll, J. F. (2014). The consequences of language proficiency and difficulty of lexical access for translation performance and priming. Memory \& Cognition, 42, 27-40.

Frenck-Mestre, C., \& Vaid, J. (1992). Language as a factor in the identification of ordinary words and number words. In R. J. Harris. Cognitive processing in bilinguals (pp. 265281). Amsterdam: Elsevier.

Gardiner, J. M., Gregg, V. H., \& Hampton, J. A. (1988). Word frequency and generation effects. Journal of Experimental Psychology: Learning, Memory and Cognition, 4, 687-693.

Giles, J., Gopnik, A., Heyman, G. D. (2002). Source monitoring reduces the suggestibility of preschool children. Psychological Science, 13, 288-291.

Glisky, E. L., Rubin, S. R., \& Davidson, P. S. R. (2001). Source memory in older adults: An encoding or retrieval problem? Journal of Experimental Psychology: Learning, Memory, and Cognition, 27, 1131-1146.

Gollan, T., \& Acenas, L. R. (2004). What is a TOT? Cognate and translation effects on tip-ofthe-tongue states in Spanish-English and Tagalog-English Bilinguals. Journal of Experimental Psychology: Learning, Memory, and Cognition, 30, 246-269.

Gollan, T. H., Forster, K. I., \& Frost, R. (1997). Translation priming with different scripts: Masked priming with cognates and non-cognates in Hebrew-English bilinguals. Journal of Experimental Psychology: Learning, Memory, and Cognition, 23, 1122-1139.

Gollan, T., Montoya, R. I., Cera, C., \& Sandoval, T. C. (2008). More use almost always means a smaller frequency effect: aging, bilingualism, and the weaker links hypothesis. Journal of Memory and Language, 58, 787-814.

Gollan, T., \& Silverberg, N. B. (2001). Tip-of-the-tongue states in Hebrew-English bilinguals. Bilingualism: Language and Cognition, 4, 63-84.

Green, D. W. (1998). Mental control of the bilingual lexico-semantic system. Bilingualism: Language and Cognition, 1, 67-81.

Green, D. W. (2005). The neurocognition of recovery patterns in bilingual aphasics. In J. F. Kroll \& A. B. De Groot (eds.), Handbook of Bilingualism: Psycholinguistic Approaches, pp. 516-530. New York: Oxford University Press.

Grosjean, F. (1988). Exploring the recognition of guest words in bilingual speech. Language and Cognitive Processes, 3, 233-274.

Grosjean, F. (1997). Processing mixed language: Issues, findings, and models. In A. M. B. de Groot \& J. F. Kroll (Eds.), Tutorials in Bilingualism Psycholinguistic Perspectives (pp. 225-253). Mahwah, New Jersey: Lawrence Erlbaum Associates.

Grosjean, F. (1998). Studying bilinguals: Methodological and conceptual issues. Bilingualism: Language and Cognition, 1, 131-149.

Grosjean, F. (2001). The bilingual's language nodes. In J.L. Nicol (Eds.), One mind, two languages: Bilingual language processing (pp. 1-22). Oxford, England: Blackwell.

Grosjean, F., \& Miller, J. L. (1994). Going in and out of languages: An example of bilingual flexibility. Psychological Science, 5, 201-206. 
Hartsuiker, R. J., \& Pickering, M. J. (2008). Language integration in bilingual sentence production. Acta Psychologica, 128, 479-489.

Hermans, D., Bongaertz, T., De Bot, K., \& Schreuder, R. (1998). Producing words in a foreign language: Can speakers prevent interference from their first language? Bilingualism: Language and Cognition, 1, 213-229.

Jared, D., \& Kroll, J. F. (2001). Do bilinguals activate phonological representations in one or both of their languages when naming words? Journal of Memory and Language, 44, 231 .

Johnson, M. K. (1988). Discriminating the origin of information. In: T. F. Oltmanns, \& B. A. Maher (Eds.), Delusional beliefs (pp. 34-65). New York: Wiley.

Johnson, M. K., Hashtroudi, S., \& Lindsay, S. D. (1993). Source monitoring. Psychological Bulletin, 114, 3-28.

Kintsch, W. (1970). Recognition memory in bilingual subjects. Journal of Verbal Learning and Verbal Behavior, 9, 405-409.

Kroll, J. F., Bobb, S. C., Misra, M., \& Guo, T. (2008). Language selection in bilingual speech: Evidence for inhibitory processes. Acta Psychologica, 128, 416-430.

Kroll, J. F., \& Stewart, E. (1994). Category interference in translation and picture naming: Evidence for asymmetric connections between bilingual memory representations. Journal of Memory and Language, 33, 149-174.

Kroll, J. F., \& Tokowicz, N. (2005). Models of bilingual representation and processing: Looking back and to the future. In J. F. Kroll \& A. B. De Groot (eds.), Handbook of Bilingualism: Psycholinguistic Approaches, pp. 531-554. New York: Oxford University Press.

Kuhl, P. K., Tsao, F. M., \& Liu, H. M. (2003). Foreign-language experience in infancy: Effects of short-term exposure and social interaction on phonetic learning. Proceedings of the National Academy of Sciences, 100, 9096-9101.

Kuhl, P. K., Williams, K. A., Lacerda, F., Stevens, K. N., \& Lindblom, B. (1992). Linguistic experience alters phonetic perception in infants by 6 months of age. Science, 255, 606608.

La Heij, W. (2005) Selection processes in monolingual and bilingual lexical access. In J. F. Kroll \& A. B. De Groot (eds.), Handbook of Bilingualism: Psycholinguistic Approaches, pp. 289-307. New York: Oxford University Press.

Levelt, W. J. M., Schriefers, H., Meyer, A. S., Pechmann, T., Vorberg, D., \& Havinga, J. (1991). The time course of lexical access in speech production: A study of picture naming. Psychological Review, 98, 122-142.

Libben, M. R., \& Titone, D. A. (2009). Bilingual lexical access in context: Evidence from eye movements during reading. Journal of Experimental Psychology: Learning, Memory, and Cognition, 35, 381-390.

Liepmann, D., \& Saegert, J. (1974). Language tagging in bilingual free recall. Journal of Experimental Psychology, 103, 1137-1141. 
Lindsay, S. D., \& Johnson, M. K. (1991). Recognition memory and source monitoring, Bulletin of the Psychonomic Society, 29, 203-205.

Lindsay, D.S., \& Johnson, M.K. (2000). False memories and the source monitoring framework: Reply to Reyna and Lloyd (1997). Learning and Individual Differences, 12, 145-161.

MacLeod, C. M., \& Kampe, K. E. (1996). Word frequency effects on recall, recognition, and word-fragment completion tests. Journal of Experimental Psychology: Learning, Memory, and Cognition, 22, 132-142.

Macnamara, J., \& Kushnir, S. L. (1971). Linguistic independence of bilinguals: The input switch. Journal of Verbal Learning and Verbal Behavior, 10, 480-487.

Marsh, R. L., Cook, G. I., \& Hicks, J. L. (2006). The effect of context variability on source memory. Memory \& Cognition, 34, 1578-1586.

McClelland, J. L., \& Elman, J. L. (1986). The TRACE model of speech perception. Cognitive Psychology, 18, 1-86.

McCormack, P. D. (1976). Language as an attribute of memory. Canadian Journal of Experimental Psychology, 30, 238-248.

Meuter, R. F. I. (2001, April). Switch costs in bilingual discourse: An exploration of relativity in language proficiency. Poster session presented at the Third International Symposium on Bilingualism, University of the West of England, Bristol, U.K.

Meuter, R. F. I. (2005). Language selection in bilinguals: Mechanisms and processes. In J. F. Kroll \& A. B. De Groot (eds.), Handbook of Bilingualism: Psycholinguistic Approaches, pp. 349-370. New York: Oxford University Press.

Meuter, R. F. I., \& Allport, A. (1999). Bilingual language switching and naming: Asymmetrical costs of language selection. Journal of Memory and Language, 40, 25-40.

Michael, E. B., \& Gollan, T. (2005). Being and becoming bilingual: Individual differences and consequences for language production. In J. F. Kroll \& A. B. De Groot (eds.), Handbook of Bilingualism: Psycholinguistic Approaches, pp. 389-410. New York: Oxford University Press.

Miller, N. A., \& Kroll, J. F. (2002). Stroop effects in bilingual translation. Memory and Cognition, 30, 614-628.

Moon, C., Lagercrantz, H., \& Kuhl, P. K. (2013). Language experienced in utero affects vowel perception after birth: A two-country study. Acta Pediatrica, 102, 156-160.

Moreno, E. M., Federmeier, K. D., \& Kutas, M. (2002). Switching languages, switching palabras (words): An electrophysiological study of code switching. Brain and Language, 80, 188207.

Myers-Scotton, C. Supporting a differential access hypothesis: Code-switching and other contact data. In J. F. Kroll \& A. B. de Groot (eds.), Handbook of Bilingualism: Psycholinguistic Approaches, pp. 326-348. New York: Oxford University Press.

Nieznański, M. (2012). Effects of generation on source memory: A test of the resource tradeoff versus processing hypothesis. Journal of Cognitive Psychology, 24, 765-780. 
Norman, D. A., \& Shallice, T. (1986). Attention to action: Willed and automatic control of behaviour. In R. J. Davidson, G. E. Schwartz \& D. Shapiro (eds.), Consciousness \& selfregulation, vol. 4, pp. 1.18. New York: Plenum Press.

O' Neill, W., \& Dion, A. (1983). Bilingual recognition of concrete and abstract sentences. Perceptual and Motor Skills, 57, 1065-1071.

Papafragou, A., Li, P., Choi, Y., \& Han, C. (2007). Evidentiality in language and cognition. Cognition, 103, 253-299.

Parker, J. F. (1995). Age differences in source monitoring of performed and imagined actions on immediate and delayed tests. Journal of Experimental Child Psychology, 60, 84-101.

Parkin, A. J., \& Leng, N. R. C. (1993). Neuropsychology of the amnesic syndrome. Hove, UK: Erlbaum.

Potter, M. C., \& Lombardi, L. (1990). Syntactic priming in immediate recall of sentences. Journal of Memory and Language, 38, 265-282.

Potter, M. C., So, K. F., Von Eckardt, B., \& Feldman, L. B. (1984). Lexical and conceptual representation in beginning and more proficient bilinguals. Journal of Verbal Learning and Verbal Behavior, 23, 23-38.

Reyna, V. F., \& Lloyd, F. (1997). Theories of false memory in children and adults. Learning and Individual Differences, 9, 95-123.

Rose, R. G., Rose, P. R., King, N., \& Perez, A. (1975). Bilingual memory for related and unrelated sentences. Journal of Experimental Psychology: Human Learning and Memory, 1, 599-606.

Ruffman, T., Rustin, C., Garnham, W., \& Parkin, A. J. (2001). Source monitoring and false memories in children: Relation to certainty and executive functioning.

Sachs, J. S. (1967). Recognition memory foe syntactic and semantic aspects of connected discourse. Perception and psychophysics, 2, 437-442.

Saegert, J., Hamayan, E., \& Ahmar, H. (1975). Memory for language of input in polyglots. Journal of Experimental Psychology: Human Learning and Memory, 1, 607-613.

Schwartz, A.I., \& Arêas da Luz Fontes, A.B. (2008). Cross-language mediated priming: Effects of context and lexical relationship. Bilingualism: Language and Cognition, 11, 1-16.

Schwartz, A. I., \& Kroll, J. F. (2006). Bilingual lexical activation in sentence context. Journal of Mermoy and Language, 55, 197-212.

Sebastián-Gallés, N., Albareda-Castellot, B., Weikum, W. M., \& Werker, J. F. (2012). A bilingual advantage in visual language discrimination in infancy. Psychological Science, 23, 994-999.

Shimamura, A. P., \& Squire, L. R. (1987). A neuropsychological study of fact memory and source amnesia. Journal of Experimental Psychology: Learning, Memory, and Cognition, $13,464-473$. 
Slotnick, S. D., Moo, L. R., Segal, J. B., \& Hart Jr., J. (2003). Distinct prefrontal cortex activity associated with item memory and source memory for visual shapes. Cognitive Brain Research, 17, 75-82.

Snodgrass, J. G., Vanderwart, M. A. (1980). A standardized set of 260 pictures: Norms for name agreement, image agreement, familiarity and visual complexity. Journal of Experimental Psychology: Learning, Memory, and Cognition, 6, 174-215.

Spivey, M. J., \& Marian, V. (1999). Cross talk between native and second languages: Partial activation of an irrelevant lexicon. Psychological Science, 10, 281-284.

Strobach, E. N., Francis, W. S., Perea, I., \& Motta, C. (2013). Recognition and repetition priming as a function of translation and sentence context. Abstracts of the Psychonomic Society, $18,149$.

Tosun, S., Vaid, J., \& Geraci, L. (2013). Does obligatory marking of source evidence affect source memory? A Turkish/English investigation. Journal of Memory and Language, 69, 121-134.

Van Assche, E., Drieghe, D., Duyck, W., Welvaert, M., \& Hartsuiker, R. J. (2011). The influence of semantic constraints on bilingual word recognition during sentence reading. Journal of Memory and Language, 64, 88-107.

Van Assche, E., Duyck, W., Hartsuiker, R. (2012). Bilingual word recognition in a sentence context. Frontiers in Psychology 3, 174.

van Hell, J., \& de Groot, A. M. B. (2008). Sentence context modulates visual word recognition and translation in bilinguals. Acta Psychologica, 128, 431-451.

van Heuven, W. J. B., Schriefers, H., Dijkstra, T., \& Hagoort, P. (2008). Language conflict in the bilingual brain. Cerebral Cortex, 18, 2706-2716.

Werker, J. F., \& Tees, R. C. (1984). Cross-language speech perception: Evidence for perceptual reorganization during the first year of life. Infant Behavior and Development, 7, 49-63.

Wheeler, M. A., Stuss, D. T., \& Tulving, E. (1997). Toward a theory of episodic memory: The frontal lobes and autonoetic consciousness. Psychological Bulletin, 121, 331-354.

Wickens, T. D. (2002). Elementary signal detection theory. Oxford University Press: New York.

Woodcock, R. W., Muñoz-Sandoval, A.F., Ruef, M. L., \& Alvarado, C. G. (2005). WoodcockMuñoz Language Survey-Revised. Rolling Meadows, IL: Riverside Publishing.

Wu, Y. J., Cristino, F., Leek, C., \& Thierry, G. (2013). Non-selective lexical access in bilinguals is spontaneous and independent of input monitoring: Evidence from eye-tracking. Cognition, 129, 418-425.

Wu, Y. J., \& Thierry, G. (2012). Unconscious translation during incidental foreign language processing. Neuroimage, 59, 3468-3473. 


\section{Appendix 1: Stimuli}

\begin{tabular}{|c|c|c|c|}
\hline $\begin{array}{l}\text { Low- } \\
\text { Frequency } \\
\text { Words } \\
\end{array}$ & Sentences & & \\
\hline alacrán & El alacrán me picó. & scorpion & A scorpion stung me. \\
\hline apio & El apio es saludable. & celery & Celery is healthy. \\
\hline ballena & La ballena es enorme. & whale & The whale is huge. \\
\hline bota & La bota tiene lodo. & boot & The boot has mud. \\
\hline bufanda & Estoy tejiendo una bufanda. & scarf & I am knitting a scarf. \\
\hline buzón & El buzon esta lleno. & mailbox & The mailbox is full. \\
\hline cacahuate & Me gusta la crema de cacahuate. & peanut & I like Peanut butter. \\
\hline calabaza & $\begin{array}{l}\text { Estoy hornenado un pay de } \\
\text { calabaza. }\end{array}$ & pumpkin & I am baking pumpkin pie. \\
\hline calcetín & Perdí un calcetin. & sock & I lost a sock. \\
\hline camello & El camello tiene sed. & camel & The camel is thirsty. \\
\hline cereza & El pay de cereza es mi favoríto. & cherry & Cherry pie is my favorite. \\
\hline chango & El chango está jugando. & monkey & The monkey is playing. \\
\hline corcho & Necesitas quitarle el corcho. & cork & You need to take the cork off. \\
\hline delfín & El delfin es un mamífero. & dolphin & A dolphin is a mammal. \\
\hline enchufe & El enchufe no está funcionando. & plug & The plug is not working. \\
\hline escoba & La bruja se montó en su escoba. & broom & The witch rode her broom. \\
\hline flauta & Yo toco la flauta. & flute & I play the flute. \\
\hline florero & El florero era de mi abuela. & vase & The vase was my grandmother's. \\
\hline fresa & La fresa de chocolate es deliciosa. & strawberry & $\begin{array}{l}\text { The chocolate strawberry is } \\
\text { delicious. }\end{array}$ \\
\hline galleta & La galleta tenía pasas. & cookie & The cookie had raisins. \\
\hline gancho & Necesito un gancho para mi traje. & hanger & I need a hanger for my suit. \\
\hline gusano & El gusano verde. & worm & The green worm. \\
\hline hongo & Hice sopa de hongo. & mushroom & I made mushroom soup. \\
\hline hormiga & La hormiga es fuerte. & ant & The ant is strong. \\
\hline jirafa & El cuello de la jirafa es largo. & giraffe & The giraffe's neck is long. \\
\hline lagartija & La lagartija toma el sol. & lizard & The lizard is taking the sun. \\
\hline langosta & La langosta es roja. & lobster & The lobster is red. \\
\hline lechuga & La lechuga es una verdura. & lettuce & Lettuce is a vegetable. \\
\hline llanta & La llanta está ponchada. & tire & My car has a flat tire. \\
\hline manguera & $\begin{array}{l}\text { Use la manguera para regar las } \\
\text { plantas. }\end{array}$ & hose & $\begin{array}{l}\text { I used the hose to water the } \\
\text { plants. }\end{array}$ \\
\hline mariposa & La mariposa voló hacia Canadá. & butterfly & The butterfly flew to Canada. \\
\hline pala & Usa la pala para la nieve. & shovel & Use a shovel for the snow. \\
\hline papalote & Vamos a volar un papalote. & kite & \begin{tabular}{|l} 
Let's fly a kite. \\
\end{tabular} \\
\hline piña & El jugo de piña es dulce. & pineapple & Pineapple juice is sweet. \\
\hline pingüino & El pinguino camina chistoso. & penguin & The penguin walks funny. \\
\hline pulpo & El pulpo tiene ocho tentáculos, & octopus & The octopus has eight tentacles. \\
\hline rana & La rana es un anfibio. & frog & The frog is an amphibian. \\
\hline
\end{tabular}




\begin{tabular}{|c|c|c|c|}
\hline silbato & $\begin{array}{l}\text { El sonido del silbato es muy } \\
\text { agudo. }\end{array}$ & whistle & $\begin{array}{l}\text { The sound of the whistle is } \\
\text { sharp. }\end{array}$ \\
\hline uvas & Las uvas saben a dulce. & grapes & Grapes taste like candy. \\
\hline zanahoria & La zanahoria es naranja. & carrot & The carrot is orange. \\
\hline $\begin{array}{l}\text { High- } \\
\text { Frequency } \\
\text { Words }\end{array}$ & Sentences & & \\
\hline árbol & El árbol da nueces. & tree & The tree grows walnuts. \\
\hline barco & El barco esta en el puerto. & ship & The ship is on port. \\
\hline botella & La botella de agua está vacía. & bottle & The water bottle is empty. \\
\hline brazo & Mi brazo se fracturó. & arm & I broke my arm. \\
\hline caballo & El caballo es negro. & horse & The horse is black. \\
\hline caja & La caja está envuelta. & box & The box is wrapped. \\
\hline cama & Alza tu cama. & bed & Make your bed. \\
\hline camisa & Mi camisa es nueva. & shirt & My shirt is new. \\
\hline casa & La casa está en la esquina. & house & The house is on the corner. \\
\hline ciudad & La ciudad no está lejos. & city & The city is not far. \\
\hline corazón & El corazón está latiendo. & heart & The heart is beating. \\
\hline cruz & La cruz es grande. & cross & The cross is big. \\
\hline dedo & $\begin{array}{l}\text { Él se quebró el dedo cuando se } \\
\text { cayó. }\end{array}$ & finger & He broke his finger when he fell. \\
\hline espejo & El espejo está quebrado. & mirror & The mirror is broken. \\
\hline fuego & $\begin{array}{l}\text { El fuego causó que se quemara el } \\
\text { bosque. }\end{array}$ & fire & $\begin{array}{l}\text { The fire caused the forest to } \\
\text { burn. }\end{array}$ \\
\hline gato & El gato desapareció. & cat & The cat disappeared. \\
\hline hombre & El hombre dejó el carro. & $\operatorname{man}$ & The man left the car. \\
\hline iglesia & Vamos a la iglesia los domingos. & church & We go to church on Sunday. \\
\hline isla & Hawaii es una isla. & island & Hawaii is an island. \\
\hline leche & La leche viene de la vaca. & milk & Milk comes from cows. \\
\hline libro & Estoy escribiendo un libro. & book & I am writing a book. \\
\hline lluvia & Tal vez caiga lluvia hoy. & rain & It might rain today. \\
\hline luna & Hoy hay luna llena. & moon & There is a full moon tonight. \\
\hline mano & Su mano estaba quebrada. & hand & The hand was broken. \\
\hline mesa & La mesa está en la cocina. & table & The table is in the kitchen. \\
\hline música & La gente escuchaba música. & music & $\begin{array}{l}\text { The people were listening to } \\
\text { music. }\end{array}$ \\
\hline nariz & La nariz de Rodolfo es roja. & nose & Rudolph's nose is red, \\
\hline niña & La niña saltó hacia el parque. & girl & The girl skipped to the park. \\
\hline ojo & $\begin{array}{l}\text { Su ojo se hincho despues de la } \\
\text { pelea. }\end{array}$ & eye & $\begin{array}{l}\text { His eye was swollen after the } \\
\text { fight. }\end{array}$ \\
\hline perro & El perro es un dalmata. & $\operatorname{dog}$ & The dog is a dalmatian. \\
\hline piedra & Hay una piedra en el camino. & rock & The is a rock on the road. \\
\hline puerta & La puerta está cerrada. & door & The door is closed. \\
\hline silla & La silla está quebrada. & chair & The chair is broken. \\
\hline sol & El sol derritió el hielo de la & sun & The sun melted the ice on the \\
\hline
\end{tabular}




\begin{tabular}{|l|l|l|l|}
\hline & carretera. & & road. \\
\hline techo & No te subas al techo. & roof & Do not get up on the roof. \\
\hline teléfono & El teléfono sonó varias veces. & telephone & $\begin{array}{l}\text { The telephone rang several } \\
\text { times. }\end{array}$ \\
\hline tren & El tren se fué de la estación. & train & The train left the station. \\
\hline ventana & La ventana necesita cortinas. & window & $\begin{array}{l}\text { The window needs some } \\
\text { curtains. }\end{array}$ \\
\hline vestido & Tú vestido azul es muy bonito. & dress & Your blue dress is pretty. \\
\hline vino & $\begin{array}{l}\text { El vino tinto combina bien con la } \\
\text { carne. }\end{array}$ & wine & Red wine goes well with meat. \\
\hline
\end{tabular}




\section{Vita}

Elva Natalia Strobach Oronoz began her undergraduate career at the University of Texas at El Paso with a double major in Organizational Communication and Psychology. She was subsequently accepted into the Language Acquisition and Bilingualism doctoral program in Psychology and has served the university in several capacities. First, Strobach Oronoz became a research associate in laboratories both in the Department of Psychology and the Department of Education. She then earned her master's degree in Experimental Psychology with an Outstanding Thesis in Psychology recognition and was able to teach two different undergraduate courses over four academic semesters earning her an Assistant Instructor Award in Psychology. Strobach Oronoz has presented her research projects at several conferences, and has secured funding for her travels through Dodson Travel Grants from the College of Liberal Arts. Her research is currently published in two journals and citations are provided below.

Francis, W. S., \& Strobach, E. N. (2013). The L2 advantage in recognition memory. Psychological Bulletin and Review, 20, 1296-1303.

Espinoza, P.P., Quezada, S. A., Rincones, R. E., Strobach, E. N., \& Estrada Gutierrez, M. A. (2012). Attributional bias instrument (ABI): validation of a measure to assess ability and effort explanations for math performance. Social Psychology of Education, 15, 533-554.

Permanent address: 1428 Luz de Sol

El Paso, Texas 79912

This dissertation was typed by Elva Natalia Strobach Oronoz. 


\footnotetext{
${ }^{\mathrm{i}}$ Age of Acquisition

ii Age Equivalency for the WMLS-R

iii Dominance as provided by the WMLS-R

${ }^{\text {iv }}$ Self-reported percentage of the time spent speaking the language

${ }^{v}$ Self-reported rating of performance in the particular task
} 